\title{
Hydrological niche segregation defines forest structure and drought tolerance strategies in a seasonal Amazon forest
}

\author{
Mauro Brum ${ }^{1 *}$ (D) | Matthew A. Vadeboncoeur ${ }^{2 *}$ | Valeriy Ivanov ${ }^{3}$ | \\ Heidi Asbjornsen $^{2,4}$ (D) | Scott Saleska ${ }^{5}$ | Luciana F. Alves $^{6}$ | Deliane Penha ${ }^{7}$ | \\ Jadson D. Dias $^{8}$ | Luiz E. O. C. Aragão ${ }^{9,10}$ | Fernanda Barros ${ }^{1}$ | Paulo Bittencourt ${ }^{1}$ | \\ Luciano Pereira $^{1}$ | Rafael S. Oliveira ${ }^{1}$
}

${ }^{1}$ Department of Plant Biology, Institute of Biology, University of Campinas - UNICAMP, Campinas, SP, Brazil; ${ }^{2}$ Earth Systems Research Center, University of New Hampshire, Durham, New Hampshire; ${ }^{3}$ Department of Civil and Environmental Engineering, University of Michigan, Ann Arbor, Michigan;

${ }^{4}$ Department of Natural Resources and the Environment, University of New Hampshire, Durham, New Hampshire; ${ }^{5}$ Department of Ecology and Evolutionary Biology, University of Arizona, Tucson, Arizona; ${ }^{6}$ Center for Tropical Research, Institute of the Environment and Sustainability, University of California, Los Angeles, California; ${ }^{7}$ Society, Nature and Development Department, Federal University of Western Pará - UFOPA, Santarém, PA, Brazil; ${ }^{8}$ Laboratory of Isotopic Ecology, Center for Nuclear Energy in Agriculture - CENA, University of São Paulo, Piracicaba, Brazil; ${ }^{9}$ Remote Sensing Division, National Institute for Space Research, São José dos Campos, SP, Brazil and ${ }^{10}$ College of Life and Environmental Sciences, University of Exeter, Exeter, UK

\section{Correspondence}

Mauro Brum, Department of Plant Biology, Institute of Biology, University of Campinas - UNICAMP, Campinas, SP, Brazil.

Email: maurobrumjr@gmail.com

\section{Funding information}

CAPES; NASA Interdisciplinary Science, Grant/Award Number: NNX14AD31G; DOE, Grant/Award Number: DESC0011078; GO-AMAZON FAPESP, Grant/ Award Number: 2013/50533-5; CNPq Productivity Fellowship, Grant/Award Number: 305054/2016-3; FAPESP-UoM, Grant/Award Number: 2014/50332-2; FAPESP-Microsoft, Grant/Award Number: 2011/52072-0

Handling Editor: Deepak Barua

\section{Abstract}

1. The relationship between rooting depth and above-ground hydraulic traits can potentially define drought resistance strategies that are important in determining species distribution and coexistence in seasonal tropical forests, and understanding this is important for predicting the effects of future climate change in these ecosystems.

2. We assessed the rooting depth of 12 dominant tree species (representing c. $42 \%$ of the forest basal area) in a seasonal Amazon forest using the stable isotope ratios $\left(\delta^{18} \mathrm{O}\right.$ and $\left.\delta^{2} \mathrm{H}\right)$ of water collected from tree xylem and soils from a range of depths. We took advantage of a major ENSO-related drought in 2015/2016 that caused substantial evaporative isotope enrichment in the soil and revealed water use strategies of each species under extreme conditions. We measured the minimum dry season leaf water potential both in a normal year (2014; $\left.\Psi_{\text {non-ENSO }}\right)$ and in an extreme drought year (2015; $\Psi_{\text {ENSO }}$ ). Furthermore, we measured xylem hydraulic traits that indicate water potential thresholds trees tolerate without risking hydraulic failure $\left(\mathrm{P}_{50}\right.$ and $\left.\mathrm{P}_{88}\right)$.

3. We demonstrate that coexisting trees are largely segregated along a single hydrological niche axis defined by root depth differences, access to light and tolerance of low water potential. These differences in rooting depth were strongly related to tree size; diameter at breast height $(\mathrm{DBH})$ explained $72 \%$ of the variation in the $\delta^{18} \mathrm{O}_{\text {xylem }}$. Additionally, $\delta^{18} \mathrm{O}_{\text {xylem }}$ explained $49 \%$ of the variation in $\mathrm{P}_{50}$ and $70 \%$ of $\mathrm{P}_{88}$, with shallow-rooted species more tolerant of low water potentials, while $\delta^{18} \mathrm{O}$ of xylem water explained $47 \%$ and $77 \%$ of the variation of minimum $\Psi_{\text {non-ENSO }}$ and $\Psi_{\text {ENSO }}$. 
4. We propose a new formulation to estimate an effective functional rooting depth, i.e. the likely soil depth from which roots can sustain water uptake for physiological functions, using $\mathrm{DBH}$ as predictor of root depth at this site. Based on these estimates, we conclude that rooting depth varies systematically across the most abundant families, genera and species at the Tapajós forest, and that understorey species in particular are limited to shallow rooting depths.

5. Our results support the theory of hydrological niche segregation and its underlying trade-off related to drought resistance, which also affect the dominance structure of trees in this seasonal eastern Amazon forest.

6. Synthesis. Our results support the theory of hydrological niche segregation and demonstrate its underlying trade-off related to drought resistance (access to deep water vs. tolerance of very low water potentials). We found that the single hydrological axis defining water use traits was strongly related to tree size, and infer that periodic extreme droughts influence community composition and the dominance structure of trees in this seasonal eastern Amazon forest.

\section{KEYWORDS}

2015 ENSO, Amazon functional diversity, cavitation, embolism resistance, hydraulic traits, root depth, stable isotopes, water potential

\section{1 | INTRODUCTION}

Water availability is one of the most important factors influencing trait evolution and plant species distribution across terrestrial ecosystems (Silvertown, Araya, \& Gowing, 2015). Indeed, drought tolerance is an important driver of species distribution across gradients of seasonality both at the local and regional scale in the Amazon forest (Bonetti, Feng, \& Porporato, 2017; Cosme, Schietti, Costa, \& Oliveira, 2017; Esquivel-Muelbert et al., 2016). Nearly half the Amazon exhibits marked seasonality in rainfall and is subject to additional high-magnitude water deficits caused by positive phases of the El Niño-Southern Oscillation (ENSO) (Jiménez-Muñoz et al., 2016; Marengo, Tomasella, Alves, Soares, \& Rodriguez, 2011). Despite these periodically adverse conditions for plant growth, trees can sustain transpiration, start new leaf flushing and maintain photosynthesis during dry periods, though the mechanisms underlying this high drought resistance are still under debate (Giardina et al., 2018; Huete et al., 2006; Malhi et al., 2009; Oliveira, Dawson, Burgess, \& Nepstad, 2005; Restrepo-Coupe et al., 2013; Saleska et al., 2003; Wu et al., 2016).

Deep rooting (Markewitz, Devine, Davidson, Brando, \& Nepstad, 2010; Nepstad et al., 1994), root hydraulic redistribution (Lee, Oliveira, Dawson, \& Fung, 2005; Oliveira et al., 2005) and root niche partitioning (Ivanov et al., 2012) are thought to be important mechanisms explaining the sustained or increased photosynthetic productivity observed during dry seasons of Amazon forests (Restrepo-Coupe et al., 2013; Wu et al., 2016). Notwithstanding, empirical data on the depth distribution of roots of different species in seasonal Amazon forests are scarce (but see Davidson et al., 2011; Markewitz et al., 2010; Moreira, Sternberg, \& Nepstad, 2000; Nepstad et al., 1994; Romero-Saltos, Sternberg, Moreira, \& Nepstad, 2005) relative to the high tree diversity in this ecosystem (Bonetti et al., 2017; Espírito-Santo, Shimabukuro, Aragão, \& Machado, 2005; Fauset et al., 2015; Steege et al., 2013). During dry periods, root systems of different morphologies can facilitate the avoidance or resistance to water stress. Deeply rooted trees can avoid the stress by accessing high water potential water in deep soils, sustaining gas exchange over longer periods of water scarcity without the need to adjust physiological regulation. Species with shallow roots are likely to become water limited, especially under high-VPD conditions common during droughts, leading to large declines in plant water potential and thus implying the need for drought tolerance strategies (Brum, Teodoro, Abrahão, \& Oliveira, 2017; Niinemets, 2010).

Xylem embolism resistance, estimated as the water potential at which plants lose $50 \%$ or $88 \%$ of their hydraulic conductance $\left(P_{50}\right.$ and $\mathrm{P}_{88}$ ), is one of the most important drought resistance traits (Anderegg et al., 2016; Meinzer, Johnson, Lachenbruch, McCulloh, \& Woodruff, 2009). This structural trait determines the range of water potentials under which plants can safely transport water without risking hydraulic failure via embolism (Bittencourt, Pereira, \& Oliveira, 2016; Hacke et al., 2007; Pereira, Domingues-Junior, Jansen, Choat, \& Mazzafera, 2017). Under water stress, plants maintain water potential within a safe range by regulating stomatal conductance, which also inevitably reduces carbon uptake (Choat et al., 
2012; Sperry, Hacke, Oren, \& Comstock, 2002). A hydraulic safety margin can be estimated as the difference between the lowest water potential observed under water-stressed conditions and $\mathrm{P}_{50}$, and is a metric that is being used as a proxy of drought vulnerability (Anderegg et al., 2016; Meinzer et al., 2009).

Given the range of structural and physiological traits allowing different water use and drought tolerance or avoidance strategies in different plant species, the hydrological niche segregation (HNS) hypothesis (Silvertown et al., 2015) proposes that within a community, plants may differ in hydraulic traits to avoid or tolerate drought along a water availability gradient to avoid competition. These traits include water uptake capability (e.g. different rooting depths or likely leaf water uptake capability), differences in stomatal control and differences in the xylem structure (Araya et al., 2011; Brum et al., 2017; Eller, Lima, \& Oliveira, 2016; Oliveira et al., 2014; Pina, Zandavalli, Oliveira, Martins, \& Soares, 2016; Vinya et al., 2013). In fact, these traits can exert a significant effect on hydrological processes (García-Baquero, Silvertown, Gowing, \& Valle, 2016) and determine differences in drought resistance strategies in Amazonian tree species (Bonetti et al., 2017; Ivanov et al., 2012). However, empirical data to test the HNS hypothesis in Amazonia are lacking. Furthermore, whether and how different hydrological niches drive differences in drought resistance traits and ecosystem processes are not fully understood (Christoffersen et al., 2016; Ivanov et al., 2012).

Natural-abundance stable isotopes of water are a useful tool for determining the depths from which plants acquire water in the soil (Dawson, Mambelli, Plamboek, Templer, \& Tu, 2002). However, this method is effective only when there is a gradient in water isotope ratios with depth, caused by evaporative enrichment at the soil surface (Berry et al., 2017). As water isotopes do not fractionate with root uptake, a tree's xylem water isotope ratio reflects the depths from which it is drawing water (Dawson et al., 2002). However, substantial depth gradients in water isotopes are not common in wet tropical forests because the rate of direct soil evaporation is slow relative to the usually continual inputs of meteoric water (Evaristo, Mcdonnell, Scholl, Bruijnzeel, \& Chun, 2016; Moreira et al., 2000). Only during extended very dry periods can surface soils in wet tropical forests become significantly isotopically enriched, allowing the use of soil water isotopes to estimate the effective rooting uptake depth at a time when water is an important limiting resource.

Here, we took advantage of the severe drought recorded in the eastern Amazon basin (Jiménez-Muñoz et al., 2016) during the 2015-2016 El Niño to investigate patterns of soil water use among trees. We sampled soil and xylem water to determine the rooting depth of various tree species (root niche partitioning), while also measuring embolism resistance and leaf water potential. We tested two hypotheses: (a) the vertical canopy position of tree species (e.g. canopy, subcanopy and understorey trees) relates directly to the vertical distribution of roots below-ground (Ivanov et al., 2012) and (b) shallow-rooted species are more drought-tolerant (i.e. feature traits leading to greater xylem embolism resistance; lower $\mathrm{P}_{50}$ ), as compared to deeply rooted species, since they are more prone to seasonal water stress under long-term drought cycles. With our results we propose a model to estimate functional rooting depth for the tropical seasonal Amazon forest.

\section{MATERIALS AND METHODS}

\section{1 | Study area}

This study was carried out in a lowland tropical rainforest in the Large-Scale Biosphere-Atmosphere km-67 experimental site at Tapajós National Forest near Santarém, Pará, Brazil (5458'W, $\left.3^{\circ} 51^{\prime} \mathrm{S}\right)$. The elevation is $185 \mathrm{~m}$ a.s.l., with topographic relief on the order of $10 \mathrm{~m}$ (IBAMA, 2004). Soil depth is greater than $12 \mathrm{~m}$ and the water-table is c. $100 \mathrm{~m}$ deep (Nepstad et al., 2002). Mean total annual precipitation (1998-2013) is 2,037 mm (Figure S1). During the prolonged dry season of 2015 (August-December), monthly precipitation averaged only $64 \mathrm{~mm}$ (Restrepo-Coupe et al., 2016). Mean annual temperature and humidity are $25^{\circ} \mathrm{C}$ and $85 \%$, respectively (Rice et al., 2004).

\subsection{Species selection}

We studied 12 locally abundant tree species occupying a range of canopy positions along the forest vertical profile (understorey, subcanopy and canopy); diameter at breast height (DBH) ranged from 3 to $159 \mathrm{~cm}$ (Table S1). Ten canopy and subcanopy species were chosen based on a long-term forest inventory database of $4 \mathrm{~km}$ of permanent transects. These 10 species represent c. $41.5 \%$ of basal area of trees $>10 \mathrm{~cm}$ DBH (Pyle et al., 2009; updated by Longo, 2013; see S1). We also sampled two very abundant understorey species in which most individuals were $<10 \mathrm{~cm} \mathrm{DBH}$ (Table S1 and S2).

\section{3 | Stable isotope analysis}

We analysed water stable isotopes $\left(\delta^{2} \mathrm{H}\right)$ and $\left(\delta^{18} \mathrm{O}\right)$ from tree xylem water and from different soil depths. To sample xylem water, we collected suberized twig segments (c. 5-10 mm diameter) within reach or by ladder for small trees, and by climbing some larger trees. From other large trees, we sampled sapwood using a 5-mm increment borer at $1.3 \mathrm{~m}$ height. For each of the 12 species, we sampled only mature individuals within a narrow $\mathrm{DBH}$ range to control for possible ontogenetic effects ( $n=3-5$ trees per species, except for Endopleura uchi where $n=1$; Table S2).

To sample soil water, we dug four pits along existing permanent survey transects and collected soil samples from six different depths $0.15,0.30,0.60,1.0,1.5$ and $2.0 \mathrm{~m}$. One additional sample was collected at $0.02 \mathrm{~m}$. We also sampled from two existing deeper pits at 4, 6, 8 and $10 \mathrm{~m}$ depths. Finally, we collected samples from two residential groundwater wells c. $15 \mathrm{~km}$ from the site, one $30 \mathrm{~m}$ deep and the other $60 \mathrm{~m}$ deep, to represent water deeper than $10 \mathrm{~m}$. For context, since we do not have rainfall isotope measurements, we used modelled precipitation isotope data to represent the regional meteoric water line (RMWL) (http://waterisotopes.org accessed 
4/20/2017; Bowen, Wassenaar, \& Hobson, 2005). We found a mismatch between the ranges covered by plant and soil $\delta^{2} \mathrm{H}$ (Figure 1a), while the range of $\delta^{18} \mathrm{O}$ observed in plant and soil samples was simi$\operatorname{lar}$ (Figure S2). For this reason, we used only $\delta^{18} \mathrm{O}_{\text {xylem }}$ as a proxy for the depth of water uptake.

All samples were quickly sealed in vials, wrapped tightly with parafilm (R) and kept frozen in the laboratory. We extracted water from soil and plant samples at UNICAMP using a cryogenic distillation method (Kryosis-HEKAtech; Ehleringer \& Dawson, 1992). Stable isotope ratios of extracted water were analysed at the Center for Stable Isotope Biogeochemistry - University of California, Berkeley, using a hot chromium reactor unit $\left(\mathrm{H} /\right.$ Device $\left.^{\mathrm{TM}}\right)$ interfaced with a Thermo Delta Plus XL mass spectrometer. Data are expressed in delta ( $\delta$ ) notation relative to Vienna mean ocean water standard (V-SMOW) (Coplen, 2011).

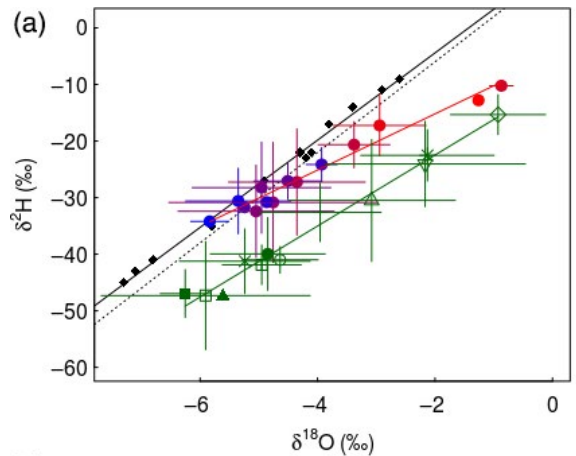

(c)

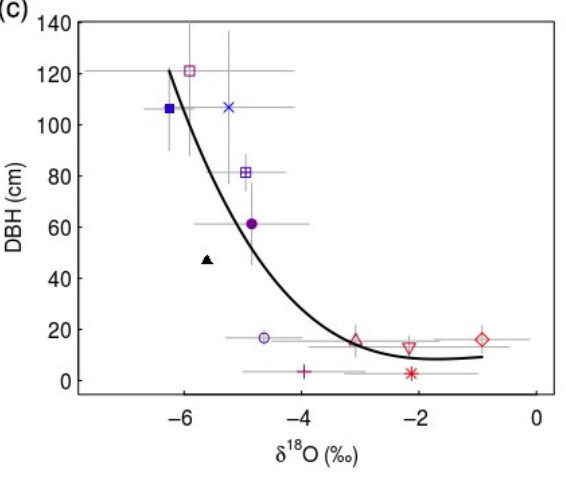

We collected all samples between 30 November and 3 December 2015, during the most extreme drought on record in this part of the Amazon basin (Jiménez-Muñoz et al., 2016), with a Palmer Drought Severity Index below -3 throughout much of the eastern Amazon. Temperatures during the 2015/2016 ENSO reached a record of $1.5^{\circ} \mathrm{C}$ higher than the maximum temperature observed in ENSO October 1997 and $2{ }^{\circ} \mathrm{C}$ higher than the peak observed in ENSO January 1983 (Jiménez-Muñoz et al., 2016).

\section{4 | Isotopic mixing model}

We used the SIMMR package in $\mathrm{R}$ to solve mixing model equations for stable isotopic data within a Bayesian framework (Parnell, 2016). The model is used to infer the proportion of water taken up from the various depths of the soil profile based on stable isotope (d)
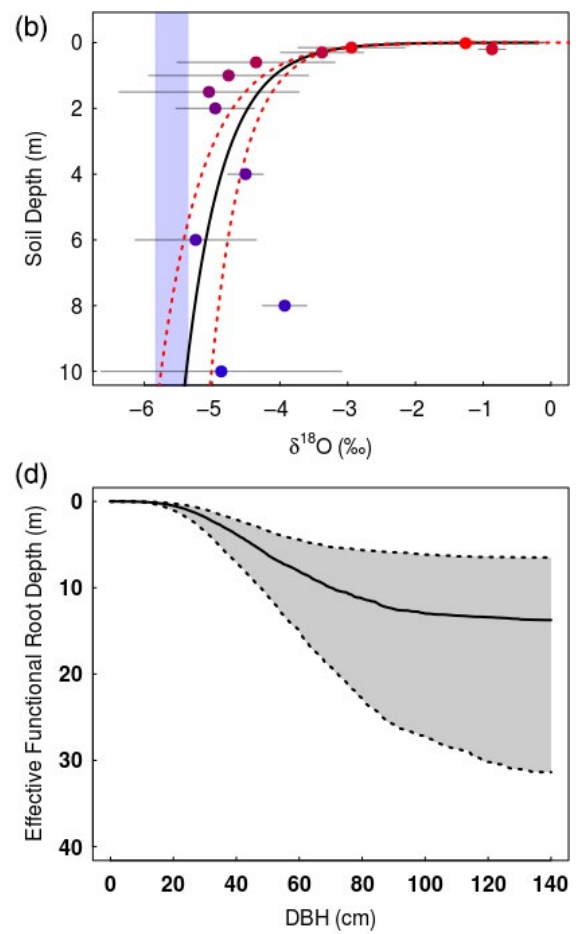

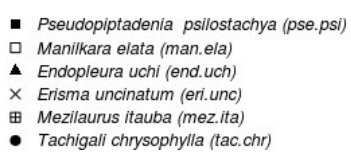

口 Manilkara elata (man.ela)

$\times$ Erisma uncinatum (eri.unc)

- Tachigali chrysophylla (tac.chi)

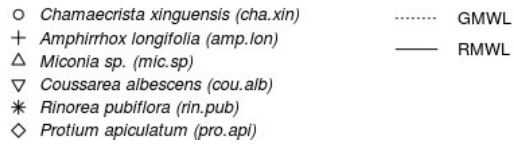

FIG URE 1 (a) Dual $\delta^{18} \mathrm{O}$ and $\delta^{2} \mathrm{H}$ stable isotope plot showing the evaporative enrichment of soil water (red to blue circles) and xylem water in trees (green line and symbols) collected during an extreme dry season in an ENSO year (2015) at the Tapajós National Forest, Brazil. Tree species symbols (green) are shown in the legend. Soil data are colour coded by depth (see panel b for depths). Black diamonds represent monthly mean meteoric water inputs. The dashed black line represents the global meteoric water line (GMWL) and the continuous black line represents the estimated regional meteoric water line (RMWL); (b) The nonlinear relationship between soil depth and $\delta^{18} \mathrm{O}_{\text {soil }}$; horizontal bars represent the standard deviation around the mean for each soil depth. The blue rectangle represents the range of mean values from samples below $10 \mathrm{~m}$ depth ( 30 and $60 \mathrm{~m}$ depths); the line represents the model of Equation (3) and the dashed red lines show the standard error of model parameters estimated with bootstrapping techniques (see Methods); (c) Average diameter at breast height (DBH) of each study species, plotted as a function of xylem water $\delta^{18} \mathrm{O}$ (a proxy of effective root depth). The line represents the nonlinear regression model of Equation (3). Error bars show one standard deviation computed from data; (d) Relationships between modelled functional root depth (EFRD) and diameter at breast height (DBH) for each individual derived from Equation (5). The continuous black line corresponds to median fitted values from bootstrapping of $m, n, k$ and $r$ parameters and used on Equation (5). The grey-shaded area delimited by dashed lines show the $25 \%$ and $75 \%$ interquartile interval around the median fitted (see Section 2) [Colour figure can be viewed at wileyonlinelibrary.com] 
observations of xylem water. The isotopic mixing model was run via the 'simmr_mcmc' function (Markov chain Monte Carlo-MCMC) to produce 1,000 iterations over four MCMC chains. In the Bayesian context, the $\mathrm{MCMC}$ repeatedly guesses the values of the water uptake proportion and finds those values that best fit the data representing different source of water to plants defined by a soil depth range (mean and standard deviation of $\delta^{18} \mathrm{O}_{\text {soil }}$ in a given soil depth). The simulations thus produce plausible contributions of each soil layer (in terms of proportion) to the xylem water isotope ratio and return a posterior distribution representing a true probability density of data (Parnell et al., 2013).

We fitted a segmented linear regression model to describe the relationship between $\delta^{18} \mathrm{O}$ and soil depth (Figure S3) using the SEGMENTED package (Muggeo, 2008). The estimated breakpoint was at $0.69 \mathrm{~m}$ depth $(S D \pm 0.17 \mathrm{~m})$. Therefore, we split the soil dataset into two distinct depth ranges: (a) shallow soil above $1 \mathrm{~m}$ depth, which has a higher proportion of fine roots, larger seasonal variation of water availability and larger macropores (Broedel, Tomasella, Cândido, \& Randow, 2017; Nepstad et al., 1994); and (b) deep soil at or below $1 \mathrm{~m}$ depth, where the soil water content is greater, roots are less abundant and percolation rates are lower (Broedel et al., 2017). The mixing model analysis was not conducted for Endopleura uchi because we only sampled one individual.

\section{5 | Embolism vulnerability measurements}

We measured xylem vulnerability to embolism as the relationship between the percentage loss of xylem conductivity (PLC) and xylem water potential ( $\Psi_{x}$ in MPa). PLC was estimated from percentage of air discharged (PAD) using the pneumatic method (Pereira et al., 2016). For the two understorey species, Rinorea pubiflora and Amphirrhox longifolia, we used the hydraulic bench method to calculate the PLC (Sperry, Donnelly, \& Tyree, 1988). Both methods provide similar estimates of $\mathrm{P}_{50}$ and $\mathrm{P}_{88}$ values (i.e. water potentials at which the PLC is 50 and 88\%; Pereira et al., 2016; Zhang et al., 2018).

For both methods, we collected branches longer than $1 \mathrm{~m}$ from two to five individuals per species, re-cut the ends under water, and let them rehydrate overnight keeping the leaves inside a plastic bag. To induce embolism, we used the bench dehydration method (Sperry et al., 1988). We measured $\Psi_{x}$ as leaf water potential $\left(\Psi_{1}\right)$, after equilibrating the branch inside a black plastic bag for at least $1 \mathrm{~h}$ prior to making the measurement, using a pressure chamber (PMS 1000; PMS Instruments Co.).

Air discharge was measured connecting the entire branch to a vacuum reservoir with $35-40 \mathrm{kPa}$ absolute vacuum pressure and calculating the amount of air discharged from the plant to the vacuum reservoir. Air discharge volume was calculated by measuring the pressure in the known volume vacuum reservoir before and after connecting to the plant and using the ideal gas law. The volume of air discharged from each branch was measured several times during branch dehydration at different leaf $\Psi_{x}$ values. PAD was calculated standardizing air discharge measurements for each branch by minimum and maximum values. Then we calculated the $P_{50}$ and $\mathrm{P}_{88}$ by fitting a Weibull function to the data:

$$
\mathrm{PAD}=\frac{100}{1+\exp \left[\frac{S_{\mathrm{p}}}{25}\left(\Psi_{x}-\Psi_{P 50}\right)\right]}
$$

where PAD is the percentage of the total air discharged, $\Psi_{\mathrm{P} 50}$ is the $\Psi_{\mathrm{x}}$ when PAD equals to $50 \%$, and $\mathrm{S}_{\mathrm{p}}$ is the slope of the curve (\% PAD/ $\mathrm{MPa})$.

For the hydraulic method, we used an ultralow flow meter to measure PLC (Pereira \& Mazzafera, 2012). Here, five segments of the base of dehydrated branches with c. 4-6 cm length and 3-5 mm diameters length were cut under water, trimmed with a razor blade and attached to the flow meter. Each segment was perfused with degasified and filtered $10 \mathrm{mmol} \mathrm{KCl}$ solution by a gravity-induced pressure head ( $>6 \mathrm{kPa}$ ) and the initial flow in each segment was measured. After the initial measurements, segments were flushed at $c$. $100 \mathrm{kPa}$ to remove all bubbles based on observation at the opposite side not attached to flow meter. The maximum flow, without embolism, was then measured. This procedure was performed in several branches at different dehydration stages. Using these measurements, we calculated the PLC curve by fitting against $\Psi_{x}$ using Equation (1).

\section{6 | Leaf water potential and hydraulic safety margin measurements}

We measured minimum leaf water potential at the peak of the dry season during a non-ENSO year (December 2014; $\Psi_{\text {non-ENSO }}$ ) and during the ENSO drought year (December 2015, $\Psi_{\text {ENSO }}$ ), using a pressure chamber (Table S1). We used fully expanded and exposed leaves, collected on sunny, rain-free days between noon and 2.30 p.m. For each species, we calculated the hydraulic safety margin (HSM) as the difference between the $\min \Psi_{\text {leaf }}\left(\Psi_{\text {non-ENSO }}\right.$ or $\Psi_{\text {ENSO }}$ ) and the $P_{50}$ or $\mathrm{P}_{88}$, to which we referred as $\mathrm{HSM}_{\mathrm{P} 50}$ and $\mathrm{HSM}_{\mathrm{P} 88}$ respectively. The HSM was calculated for both the ENSO and non-ENSO years

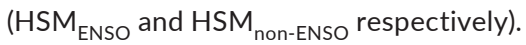

\section{7 | Statistical analysis}

We used R 3.3.3 to perform all statistical analyses (R Core Team, 2017). We tested whether the effect of depth on $\delta^{18} \mathrm{O}$ of soil water was strong enough to differentiate the various parts of the soil profile using linear and multiple nonlinear models. We used the AIC criterion to choose the best model to describe this relationship (Burnham \& Anderson, 2003).

To test the hypothesis that the vertical canopy position of tree species relates directly to the vertical pattern of water uptake by trees, we used linear regression to test for covariation between $\mathrm{DBH}, \delta^{18} \mathrm{O}_{x y l e m}$ and the proportion of water uptake from the mixing model. We also used linear regression to quantify the covariation between the uptake depths and xylem resistance to embolism traits. We performed a post hoc multiple-comparisons Tukey test to identify taxonomic groups with similar estimated effective rooting 
FIGURE 2 (a) Proportion of water use from shallow (<1 m; red) and deep (>1 m; blue) derived from the isotopic mixing model. Error bars show one standard deviation. Species are sorted from left to right with increasing average $\mathrm{DBH}$; species name abbreviations are described in Figure 1; (b) Nonlinear relationships between the mean $\mathrm{DBH}$ of each species and the proportion of water uptake from deep soil. Species symbols follow the legend in Figure 1 [Colour figure can be viewed at wileyonlinelibrary.com]
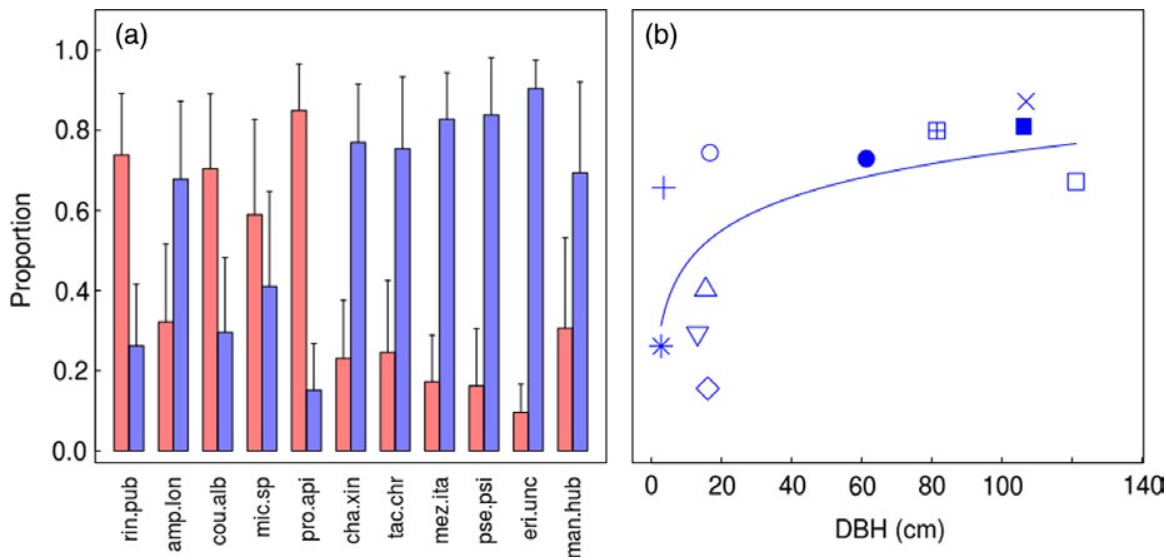
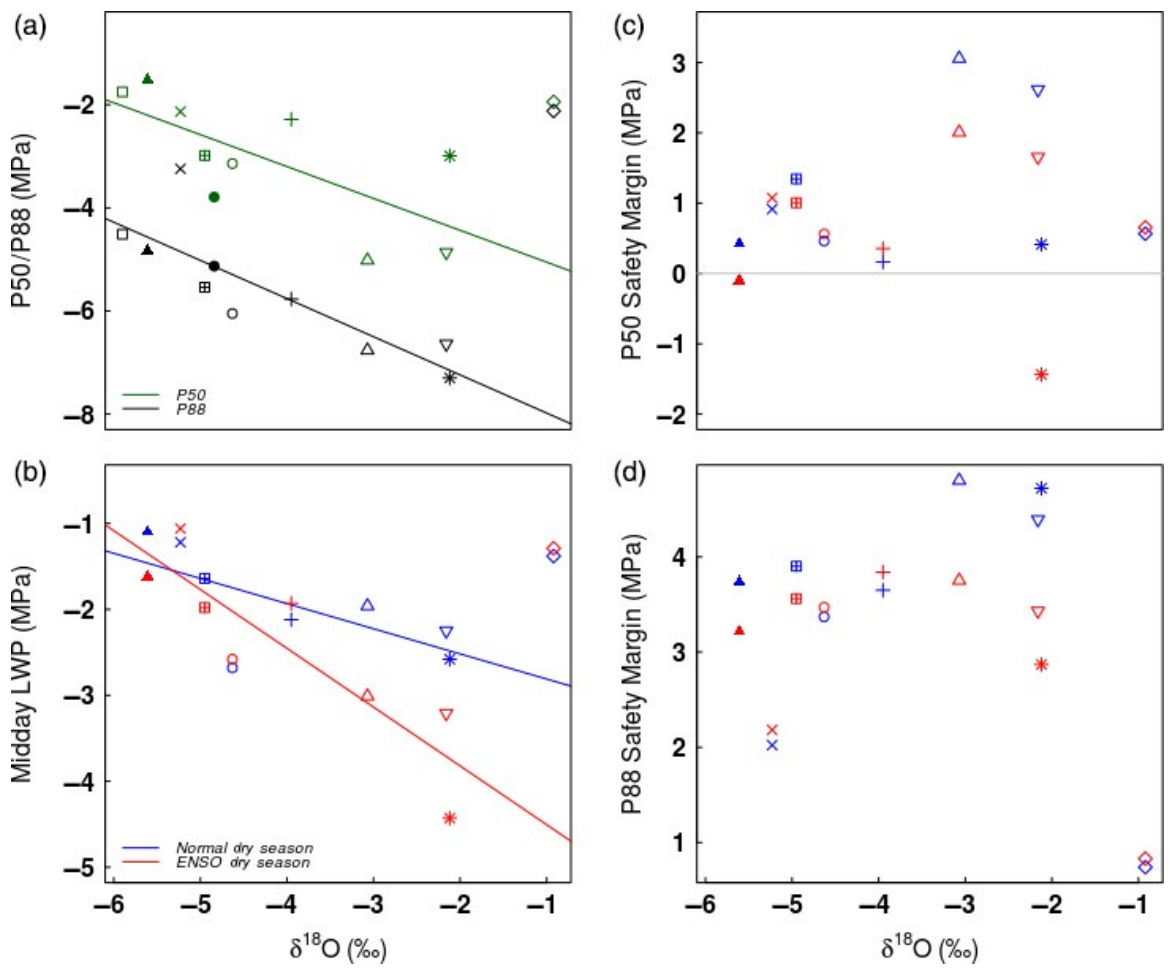

FIGURE 3 Relationships between xylem $\delta^{18} \mathrm{O}$ (used as proxy of functional root depth during an extreme dry season in December 2015) and hydraulic traits of the study species. The lines represent linear regressions when significant; $p<0.05$. (a) $P_{50}$ (green) and $P_{88}$ (black); (b) Midday leaf water potential (LWP) measured during peak of a normal dry season in December 2014 (blue) and at the peak of an extreme ENSO dry season in December 2015 (red); (c and d) Hydraulic safety margins calculated relative to $\mathrm{P}_{50}\left(\mathrm{HSMP}_{50}\right)$ and $\mathrm{P}_{88}\left(\mathrm{HSMP}_{88}\right)$ safety margins calculated for normal (blue) and ENSO (red) dry seasons. Species symbols follow the legend in Figure 1 [Colour figure can be viewed at wileyonlinelibrary.com]

depth. We also tested the validity of bivariate models derived here, using observed vs. predicted variables by linear models. In order to assess error magnitude, we estimated the root-mean-squared deviation (RMSD) as

$$
\mathrm{RMSD}=\sqrt{\frac{1}{n-1} \sum_{i=1}^{n}(\text { pred }- \text { obs })^{2}}
$$

which represents the mean deviation of the predicted value in relation to the observed value, in the same units as the variable under evaluation (Piñeiro, Perelman, Guerschman, \& Paruelo, 2008). We used an ANCOVA to identify differences in slopes of the relationship between $\delta^{18} \mathrm{O}$ and $\delta^{2} \mathrm{H}$ for the regional meteoric water line and the water lines representing the xylem and soil water samples.

\subsection{Effective functional rooting depth}

We used the observed relationships of oxygen isotopes with depth in soil water (Figure 1b), and with tree size in xylem water (Figure 1c), to construct a model to infer the effective functional rooting depth (EFRD), or depth of root water uptake, for any individual tree of known size. Specifically, we fit models to describe the relationships between observed tree diameter, and xylem 
$\delta^{18} \mathrm{O}$, and between soil water $\delta^{18} \mathrm{O}$ and depth. Firstly, we fit a model describing xylem $\delta^{18} \mathrm{O}$ as a function of $\mathrm{DBH}$ (i.e. the inverse of relationship in Figure 1c):

$$
\delta^{18} \mathrm{O}=k \cdot\left[1-\exp ^{(\mathrm{r} \cdot \mathrm{DBH})}\right]
$$

Secondly, we fit a model for soil depth predicted $\left(Z_{\text {soil }}\right)$ as a function of soil water $\delta^{18} \mathrm{O}$ (Figure $1 \mathrm{~b}$ ):

$$
Z_{\text {soil }}=\exp \left(\frac{\delta^{18} \mathrm{O}-\mathrm{m}}{n}\right)
$$

Combining Equations (3) and (4) yields (Figure 1d; black line):

$$
E F R D=\exp \left\{\frac{\left[k \cdot\left(1-\exp ^{(r \cdot D B H}\right)-m\right]}{n}\right\}
$$

EFRD is computed on a continuous basis, and its minimum and maximum values depend on the $\mathrm{DBH}$ distribution of stems within the plot. To account for the effect of uncertainty of the parameters fit in Equations (3) and (4) on the predictions of Equation (5), given the observed variations in $\delta^{18} \mathrm{O}_{\text {soil }}$ with soil depth and in $\delta^{18} \mathrm{O}_{\text {xylem }}$ with tree size in larger trees (larger $\mathrm{DBH}$ ), we performed a bootstrapping analysis to propagate the uncertainty of the $m, n, k$ and $r$ parameters (Davison \& Hinkley, 1997). We started by creating a 1,000 bootstrap replicate sets sampling from the data with replacement combinations of $\delta^{18} \mathrm{O}_{\text {soil }}$ and $\delta^{18} \mathrm{O}_{\text {xylem }}$ (the boot [Canty \& Ripley, 2016] and nlstools [Baty et al., 2015] packages in R software were used). Using these replicate sets, we obtained the $m, n, k$ and $r$ parameters by applying the fitting procedures to Equations (3) and (4). Each bootstrap replicate set of parameters thus yielded a realization of the functional dependence of Equation (5). The median EFRD fit (i.e. based on 1,000 realizations for each DBH) was taken as the representative form of this dependence (shown as the black line in Figure $1 \mathrm{~d}$ ), with the corresponding $m, n, k$ and $r$ parameter set considered as "optimal". We used this optimal set to evaluate EFRD for all trees in the census inventory for the km-67 study site (4 ha area total, Pyle et al., 2009 updated by Longo, 2013).

To evaluate the EFRD at the ecosystem level for this site, we calculated the community-weighted mean EFRD (following Muscarella \& Uriarte, 2016 for community traits generally). For that, we aggregated inventory data according to taxa (species, genera and families): we averaged EFRD (obtained for individual trees) within each taxa and weighted each taxon-specific EFRD by the corresponding dominance, based on its fraction of total stem basal area at the site.

\section{3 | RESULTS}

\subsection{Water stable isotopes revealed species differences in rooting depth}

The extreme drought in 2015 caused substantial evaporative isotope enrichment in the first meter of soil in the Tapajós forest, which allowed us to estimate a gradient of rooting depth of tree species in Amazonia using natural-abundance stable isotopes of oxygen (Figure 1a,b). Overall, soil depth explained $68 \%$ of the average $\delta^{18} \mathrm{O}_{\text {soil }}$ variability (Table 1 ). Based on the regression model with a segmented relationship between $\delta^{18} \mathrm{O}_{\text {soil }}$ and soil depth, the breakpoint in the $\delta^{18} \mathrm{O}_{\text {soil }}$ depth profile was $0.69 \mathrm{~m}$ (Figure S3, SE $= \pm 0.17 ; r^{2}=0.82 ; p<0.01$ ). Splitting the soil data into two categories based on this threshold as explained above, the average $\delta^{18} \mathrm{O}_{\text {soil }(<1 \mathrm{~m})}$ was $-3.08 \%$ o $(S D= \pm 1.38)$, whereas the average $\delta^{18} \mathrm{O}_{\text {soil (>1) }}$ of deeper soil layers were less enriched in $\delta^{18} \mathrm{O}(-4.95 \pm 0.95 \%$ o). Well water from 30 to $60 \mathrm{~m}$ depth was the most depleted, with $\delta^{18} \mathrm{O}_{\text {soil }}$ varying from $-5.85 \%$ o to $-5.35 \%$ (Figure $1 \mathrm{~b}$; blue rectangle), similar to that of the annual mean for precipitation ( $\delta^{18} \mathrm{O}=-5.7 \%$; Figure $\left.1 \mathrm{a}\right)$.

The slope of the regional meteoric water line (RMWL)

\begin{tabular}{|c|c|c|c|c|c|c|c|c|}
\hline Linear models & $r^{2}$ & $F$ & $d f$ & $p<$ & a & b & c & Figure \\
\hline $\log \left(\right.$ Soil Depth): $\delta^{18} \mathrm{O}_{\text {soil }}$ & 0.68 & 8.77 & 12 & 0.001 & -1.22 & -4.5 & - & $1 b$ \\
\hline DBH: $\delta^{18} \mathrm{O}_{x y l e m}^{a}$ & 0.72 & 12.13 & 9 & 0.01 & -1.95 & 10.32 & -0.76 & $1 d$ \\
\hline SWUP: $\log (\mathrm{DBH})$ & 0.41 & 6.46 & 9 & 0.05 & -0.12 & 0.81 & - & $2 b$ \\
\hline DWUP: $\log (\mathrm{DBH})$ & 0.41 & 6.46 & 9 & 0.05 & 0.18 & 0.12 & - & $2 b$ \\
\hline$P_{50}: \delta^{18} O_{x y l e m}^{b}$ & 0.47 & 7.702 & 8 & 0.02 & -3.10 & -0.29 & - & 3 \\
\hline$P_{88}: \delta^{18} O_{\text {xylem }}^{b}$ & 0.70 & 19.32 & 8 & 0.001 & -0.74 & -8.7 & - & 3 \\
\hline $\mathrm{MLWP}_{\text {normal }}: \delta^{18} \mathrm{O}_{\text {xylem }}$ & 0.47 & 5.32 & 6 & 0.06 & -0.29 & -3.10 & - & 3 \\
\hline MLWP $_{\text {ENSO }}: \delta^{18} \mathrm{O}_{\text {xylem }}$ & 0.77 & 20.98 & 6 & 0.01 & -0.68 & -5.19 & - & 3 \\
\hline $\mathrm{ADo}_{(\mathrm{DBH})}: \mathrm{EFRD}$ & 0.63 & 15.62 & 9 & 0.001 & -0.20 & 4.33 & - & S7 \\
\hline
\end{tabular}
(slope $=7.70$; intercept $=10.99$ ) is 0.30 , which is lower than the global

TAB LE 1 Results for linear models (response: predictive) performed

${ }^{a}$ The $\mathrm{DBH}: \delta^{18} \mathrm{O}_{\text {xylem }}$ is a polynomial relationship given by $\mathrm{DBH}=\mathrm{b}+\mathrm{a}\left(\delta^{18} \mathrm{O}\right)^{2}+\mathrm{c}\left(\delta^{18} \mathrm{O}\right)^{3}$.

${ }^{\mathrm{b}}$ After removal of Protium apiculatum, which was an outlier.

SWUP: shallow (<1 m) water use proportion; DWUP: deep (>1 m) water use proportion; MLWP: midday leaf water potential; ADo $_{(\mathrm{DBH})}$ : absolute dominance of each DBH class. $\mathrm{P}_{50}$ : water potential at which plants lose $50 \%$ of their hydraulic conductance; $\mathrm{P}_{88}$ : water potential at which plants lose $88 \%$ of their hydraulic conductance; DBH: diameter at breast height; EFRD: estimated functional root depth. 
TABLE 2 ANCOVA statistics comparing the slopes of linear relationships between $\delta^{18} \mathrm{O}$ and $\delta^{2} \mathrm{H}$

\begin{tabular}{lcccll} 
ANCOVA & $\boldsymbol{F}$ & $\mathbf{d f}$ & AIC & $\boldsymbol{p}$ & Slope difference \\
\hline RMWL: SWEL & 65.64 & 1 & 92.67 & 0.001 & -2.74 \\
\hline GMWL: RMWL & 6.127 & 1 & 64.12 & 0.01 & -0.29 \\
RMWL: PWEL & 97.37 & 1 & 87.51 & 0.001 & -1.43 \\
SWEL: PWEL & 17.60 & 1 & 101.50 & 0.003 & -1.30 \\
\hline
\end{tabular}

GMWL: global meteoric water line; RMWL: regional meteoric water line; SWEL: soil water evaporative line; PWEL: plant water evaporative line. meteoric water line (GMWL) (ANCOVA; Table 2; $p<0.01$ ). The soil evaporative line slope was 2.74 , which is lower than the RMWL slope (Figure 1a; Table 2). The $\delta^{18} \mathrm{O}_{\text {xylem }}$ ranged from $-0.92 \%$ o to $-6.25 \%$ o suggesting a large diversity of rooting depths for this community (Figure 1a). These data fall along a line with slope 1.43 lower than RMWL slope (slope $=6.27$; intercept $=-9.92$; Figure $1 \mathrm{a}$; Table 2 ), but higher than the soil evaporative line (ANCOVA; Table 2).

Species differed systematically in the contribution of water uptake from different depths. The mixing model showed that four species used mostly shallow soil water $(<1 \mathrm{~m})$, while six species derived at least $50 \%$ of their water from soils deeper than $1 \mathrm{~m}$ (Figure $2 \mathrm{a}$ ). Rooting depth (using $\delta^{18} \mathrm{O}$ as a proxy) was strongly related to the stem size differences across the species (Figure 1c; $r^{2}=0.72$; $p<0.01)$. With the exception of the understorey species A. longifolia, smaller trees (DBH $<30 \mathrm{~cm}$ ) mostly used water from the soil above $1 \mathrm{~m}$ depth $\left(r^{2}=0.41 ; \mathrm{p}<0.05\right.$; Table 1$)$, while large trees (DBH $>40 \mathrm{~cm})$ mostly used water from deeper soil $\left(r^{2}=0.41 ; p<0.05\right.$; Table 1; Figure 2b).

\subsection{Hydraulic traits and their relationships with rooting depth}

Among the species in our survey (Figure $3 a$ ), $\mathrm{P}_{50}$ ranged from -5.01 to $-1.52 \mathrm{MPa}$ and $\mathrm{P}_{88}$ ranges from -7.29 to $-2.12 \mathrm{MPa}$. The variation of $\delta^{18} \mathrm{O}_{\text {xylem }}$ explained $49 \%$ of the variation in $\mathrm{P}_{50}$ and $70 \%$ of $\mathrm{P}_{88}$ (Table 1; $p<0.05$ ), after removal of Protium apiculatum, which was an outlier as evaluated by Cook's distance inspection (Aguinis, Gottfredson, \& Joo, 2013). During a non-ENSO year, the minimum $\Psi_{\text {non-ENSO }}$ ranged from $-2.68 \mathrm{MPa}$ to $-1.10 \mathrm{MPa}$. The extreme ENSO drought increased the variation of leaf water potential; $\Psi_{\text {ENSO }}$ ranges from -4.43 to $-1.06 \mathrm{MPa}$ (Figure $3 \mathrm{~b}$ ).

We observed a higher tolerance of low water potential in shallow-rooted species. Here, the variation of $\delta^{18} \mathrm{O}_{\mathrm{xylem}}$ explained $47 \%$ and $77 \%$ of the variation of minimum $\Psi_{\text {non-ENSO }}$ and $\Psi_{\text {ENSO }}$ respectively (Table 1; $p=0.06$ and $p<0.01$ ). Trees with more enriched xylem water (i.e. taken up from shallow soil) exhibited lower leaf water potentials in both non-ENSO and ENSO years (Figure $3 \mathrm{~b}$ ). The $\mathrm{HSMP}_{50}$ and $\mathrm{HSMP}_{88}$ during normal and ENSO years were always positive or very close to zero. The exception was the shallow-rooted species Rinorea pubiflora, which showed $-1.43 \mathrm{HSMP}_{50}$ during the ENSO year (Figure 3c). Furthermore, there was no relationship between $\delta^{18} \mathrm{O}_{\text {xylem }}$ and $\mathrm{HSMP}_{50}$ and $\mathrm{HSMP}_{88}$ during normal or ENSO years (Figure 3c,d).

\subsection{Effective functional rooting depth model}

The models described in Equations (3)-(5) were used to scale-up the overall pattern of effective rooting depth to the whole forest community at Tapajós (Figure 1d). For Equation (3), the parameters derived from EFRD fit, based on 1,000 realizations for each DBH and considered as "optimal" representative form of this dependence are $k=-5.356$ and $r=-0.0516$. In this case, the $\delta^{18} \mathrm{O}_{\text {predicted }}$ explained $52 \%$ of the variation of xylem $\delta^{18} \mathrm{O}_{\text {observed }}$ $\left(r^{2}=0.52 ; p=0.002 ;\right.$ RMSD $=1.35 \%$; Table S2). The bootstrapping approach estimates the parameters as $k=-5.579(S E=0.62)$ and $r=-0.061$ ( $S E=0.03$ ). For Equation (4), using the same approach of Equation (3), the parameters derived are $m=-3.829$ and $n=-0.588$. In this case, the predict $Z_{\text {soil }}$ explained $84 \%$ of the variation of $Z_{\text {soil }}$ observed $\left(r^{2}=0.84 ; p<0.001 ; R M S D=12.9 \mathrm{~m}\right.$; Figure S4). Here, the results from bootstrapping were $m=-4.076$ $(S E=0.157)$ and $n=-0.567$ (SE =0.087; Figure 1c). The model's deviation from the 1:1 line indicates that this prediction was biased to shallow soil (modelled line below 1:1 line). Despite the larger differences between predicted values and observed values $($ RMSD = $12.9 \mathrm{~m}$ ), we used our model derived from Equation (5) to extrapolate the EFRD to the larger km-67 study area at Tapajós Forest. The estimated average maximum EFRD based on the maximum DBH measured within the plot was 13.33 m (25\%-75\% interquartile interval: $6.73 \mathrm{~m}$ to $30.14 \mathrm{~m}$ ).

\section{4 | Scaling rooting depth estimates to the ecosystem}

Our estimates of ecosystem-scale rooting depth distribution indicated a disproportionate number of individuals drawing water from depths shallower than $1.32 \mathrm{~m}$ (Median $=0.24 \mathrm{~m}$; Mean $=1.32 \mathrm{~m}$ ). The dry season community-weighted mean of EFRD was $3.56 \mathrm{~m}$. There were specific families, genera and species restricted to drawing water from shallow soil and others exclusively drawing water from deep soil, as dictated by their $\mathrm{DBH}$ distribution in the studied ecosystem. This was also confirmed when we contrasted the $10 \%$ most dominant taxa (higher absolute dominance $\left(\mathrm{ADo}_{(\mathrm{DBH})}: \mathrm{m}^{2} / \mathrm{ha}\right)$, as shown in Figures $\mathrm{S} 5$ and $\mathrm{S} 6$ that illustrate differences in EFRD based on multiple group comparison (Tukey HSD Test; $p<0.05$ ). The scatterplot showing the variations in EFRD (hydrological axis) and DBH (light availability axis) across taxa suggests a single predominant axis of variation 

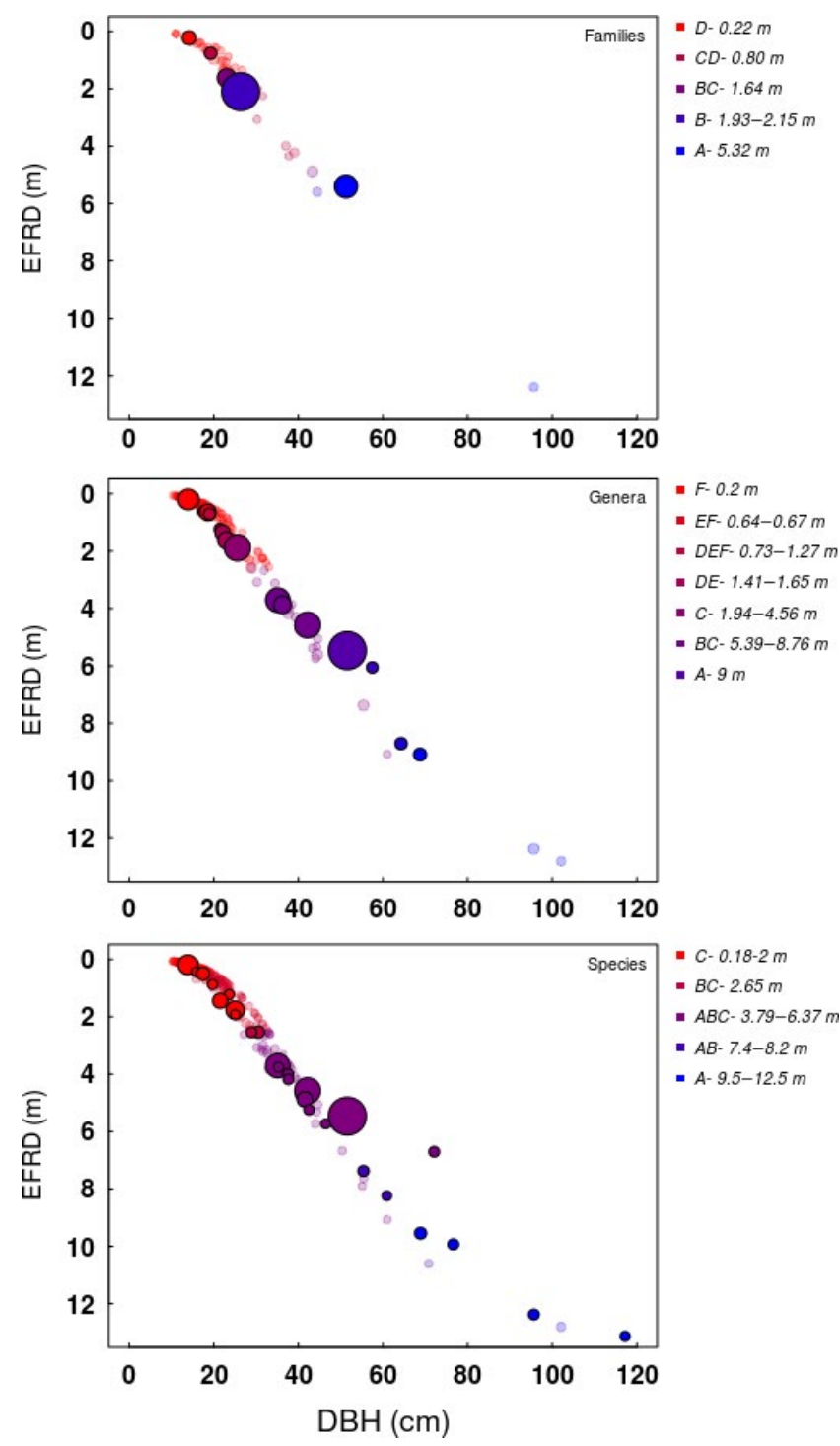

FIGURE 4 Hydrological niche axis given by the average estimated functional root depth (EFRD) as a function of the average diameter at breast height (DBH), a proxy for light availability. From top to bottom is the average value from both parameters for family, genus and species level. The circle size is proportional to dominance $\left(\mathrm{m}^{2} / \mathrm{ha}\right.$ ) of the $10 \%$ most dominant taxa at each level (see Figure $\mathrm{S} 6$ ). The lightly shaded circles represent all tree taxa at Tapajós (see Figure S5). Colours represent the post hoc Tukey comparison results of EFRD to each taxonomic level. The letters on right legend indicate differences between groups defined by post hoc Tukey statistical differences on the EFRD range $(p<0.05)$ and the depth range of EFRD where each correspondent group belongs (see also Figure S4) [Colour figure can be viewed at wileyonlinelibrary.com]

representing a niche spectrum defined jointly by access to water and light (Figures 1c and 4). Differences in circle sizes given by post hoc Tukey test also show that only a few taxonomic groups are more dominant than others (Figure 4). The limited overlap between circles demonstrates the segregation of taxa along a single niche axis of light-water availability, from lower light availability and restricted water access, to higher light availability and deep water access (Figure 4; Figure S6). By pooling individuals into DBH classes (every $10 \mathrm{~cm}$ ) to calculate the absolute dominance of each class $\left(\mathrm{ADo}_{(\mathrm{DBH})}\right)$, we found a linear negative response of $A D o_{(\mathrm{DBH})}$ as a function of EFRD (Figure S7; $r^{2}=0.63$; Table 1 ).

\section{4 | DISCUSSION}

Our results provide strong evidence for segregation of root water uptake in soil as an important strategy allowing multispecies coexistence in a seasonal Amazon forest. Specifically, using $\delta^{18} \mathrm{O}$ to estimate the effective rooting depth, we empirically confirmed a modelling-based hypothesis (Ivanov et al., 2012) that the aboveground vertical structure is related to rooting depth distribution (Figure 1c). Furthermore, we showed that greater rooting depth (using $\delta^{18} \mathrm{O}$ as proxy of root depth) is associated with lower xylem resistance to embolism across taxa. Shallow-rooted species, which dominate the understorey, compensate for only having access to shallow soil with lower water potentials by having greater xylem resistance to embolism (i.e. lower $\mathrm{P}_{50}$ and $\mathrm{P}_{88}$; Figure $2 \mathrm{a}$ ) and anisohydric stomatal control strategy (Tardieu, 1996), demonstrated by their weaker year-to-year water potential regulation even during an extreme 2015/2016 ENSO drought (Figure 3b). Our results also demonstrate, for the first time, the functional integration of below- and above-ground hydraulic traits as drivers of drought avoidance and drought tolerance strategies for Amazon tree species. These results support the niche theory in tropical forests where it is expected that plant species strategies range from acquisitive with high growth rates at high resource levels (e.g. light and water) to more conservative, slowly growing species that are tolerant of shade and drought (Sterck, Markesteijn, Schieving, \& Poorter, 2011). Additionally, our rooting depth results coupled with forest structure parameters allowed the development of a new formulation to estimate the effective functional rooting depth (EFRD), defined as the likely soil depth from which roots can sustain water uptake for physiological functions (Figure 1d). The EFRD will be useful to modellers interested in integrating the coordination between below- and above-ground plant functions into predictions of forest productivity responses and forest resilience to climate change forecasts in seasonal Amazonia (Christoffersen et al., 2016; Fan, Miguez-Macho, Jobbágy, Jackson, \& Otero-Casal, 2017; Ivanov et al., 2012; Markewitz et al., 2010; Meir et al., 2009; Restrepo-Coupe et al., 2016).

\subsection{Ecological implications of soil vertical root partitioning}

The strong relationship between functional rooting depth and tree size (Figure 1b, Equation 3 ) that was used to scale our results to the ecosystem level suggests that soil water and light, which both vary seasonally, are the resources for which trees must compete most strongly in this seasonal Amazon forest, and that resource partitioning contributes to species coexistence (Sterck et al., 2011). Indeed, the distributions of leaf area and light environments are strongly related to DBH distribution of trees in Tapajós, as individuals optimize 
their productivity over the vertical gradient to create consistent relationships between canopy light environments and biomass growth (Stark et al., 2012, 2015). Our results further suggest that rooting depth increases with tree height, compensating for the greater evaporative demand at the top of the canopy (McDowell \& Allen, 2015) and allowing larger trees to be photosynthetically active during the dry season (Giardina et al., 2018). The greater light interception of taller trees may allow them to afford the carbon costs of growing deeper roots. Based on water isotopes in xylem and soil water, our estimates show that maximum effective root depth can be as deep as c. $13 \mathrm{~m}$ (Figure 1d, black line; Table S2). This deeper root investment may be attributed to the temporal variability of water availability in Tapajós, inducing deep-root investment to reduce water stress and competition during extreme dry conditions. These belowground allocation rules force a trade-off at the community level between light use (Stark et al., 2015; Wu et al., 2016) and water use strategies (Ivanov et al., 2012). Although whether rooting depth and drought tolerance correlate with phenological strategies remains to be tested, we would expect the leaf phenology of canopy trees to respond more to light availability than water, while the phenology of shallow-rooted smaller trees would be driven mostly by water availability.

The spatial variation in light and water ("eco-hydro-light" niche axes) along vertical profiles drives niche partitioning, and forest structural and taxonomic organization within the Tapajós community (Figure 4). We found specific groups of families (five), genera (seven), and species (five) dominating a range of soil depths and canopy layers (given by DBH variance) (Figure 4, Post hoc Tukey clustering, see legend). Among the $10 \%$ most dominant groups of species, genera and families, there is a relatively limited overlap in EFRD. These results illustrate above- and below-ground space partitioning at a fine scale by the most dominant groups and represent an average distance sufficiently small for species to minimize competition and dominate in each niche of light (Kohyama, 1993; Stark et al., 2012) and water availability (Araya et al., 2011). The strength of interspecific interaction among coexisting dominant species may reflect the distribution of long-term hydraulic traits selected within the community (Hillebrand, Bennett, \& Cadotte, 2008). In fact, we showed a diversity of drought-related strategies dependent on rooting depth, xylem embolism resistance (Figure 2), and above-ground forest vertical structure that might help explain the dominance structure of the Tapajós forest community.

We estimated an effective rooting depth for the whole community as c. $3.6 \mathrm{~m}$, considering the community-weighted EFRD mean by species dominance. The weighted EFRD mean shows the proportional influence of the dominant species (Muscarella \& Uriarte, 2016) and determines the depth with the greatest influence on water use in Tapajós, indicating the depth at which most of the water extraction occurs during dry season. These results indicate the prevalence of a drought avoidance strategy defined by deeper water access to mitigate the seasonal and interannual drought cycles. Indeed, quantification of fine-root vertical profiles showed only c. $10 \%$ of the total root mass occurred between 4 and $10 \mathrm{~m}$ in the eastern Amazon
(Nepstad et al., 1994). A tracer-water experiment suggested water access by dominant mid-canopy Coussarea racemosa (=C. albicans), Sclerolobium chrysophyllum (=Tachigali chrysophylla) and Eschweilera pedicellata around 2-m depth (Romero-Saltos et al., 2005). During a throughfall exclusion (artificial drought) experiment conducted in Tapajós, based on measures of soil electrical resistivity, it was observed that deep-root water uptake increased up to $18 \mathrm{~m}$ in the treatment, in contrast with the control plot (Davidson et al., 2011). Furthermore, root systems may allow the hydraulic redistribution of water from shallow to deep soil (downward) for storage during the onset of the wet season; or the transfer of stored water from deep to shallow soil (upward) to meet the demand by plants during the dry season (Lee et al., 2005), as has been documented in Manilkara elata, Protium robustum and Coussarea racemosa (=C. albicans), which are dominant species at our site (Oliveira et al., 2005).

Shallow-rooted small trees, between 20 and $30 \mathrm{~cm}$ diameter (Figure S4) are quite abundant, representing $45 \%$ of the forest above-ground biomass in Tapajós (Vieira et al., 2004). This structural pattern contributes to the median EFRD at a shallow soil depth (c. $0.37 \mathrm{~m}$ ), indicating high competition for water uptake in this layer. When water is abundant during the rainy season, competition for water is not very important relative to other resources, such as nutrients and light. However, the high climatic variability and the persistently high water demand during the dry season forces a trade-off in terms of tree water use at the community level (Schwinning \& Kelly, 2013). Moreover, considering the reduced light availability for understorey trees during the rainy season (Huete et al., 2006; Restrepo-Coupe et al., 2013), the relatively abundant light during the dry season is a window of opportunity for these trees to maximize productivity, which must be sustained by their strategy of drought tolerance. The regular seasonal cycle of water scarcity and the frequent droughts in the eastern Amazon appear to have selected for species that are successful at either avoiding or tolerating water stress, as indicated by the great range of $\mathrm{P}_{50}$ and $\mathrm{P}_{88}$ we observed (Figure 3).

We showed that $\delta^{18} \mathrm{O}$ variance (a proxy for rooting depth) explained $40 \%$ and $70 \%$ of species-specific variation in $P_{50}$ and $P_{88}$, respectively. Shallow-rooted trees had greater xylem resistance to embolism formation, i.e. the lower $P_{50}$ and $P_{88}$ values down to $-5 \mathrm{MPa}$ and $-7.29 \mathrm{MPa}$, as compared to deeply rooted trees that do not require such high tolerance due to their access to a larger reservoir of deep water (Figure 3a). Consequently, shallow-rooted species showed greater decreases in leaf water potential and hydraulic safety margin than deep-rooted species during the extreme 2015 drought (Figure $3 d$ and Figure S7). This suggests that shallow-rooted species can tolerate a certain degree of embolism to maintain carbon uptake under dry conditions (Meinzer et al., 2009), although most species presented positive safety margins. For instance, the higher seasonal changes in hydraulic safety margins for shallow-rooted understorey species (Figure 3) reinforce the notion that this group of species can decrease their water potential and operate under a narrow safety margin in order to keep their stomata open and maintain gas exchange during the opportunistic time of higher light level (with 
exception of Protium apiculatum, which was very vulnerable to embolism and showed relatively little variation in leaf water potential). Indeed, the shallow-rooted R. pubiflora experienced the most negative leaf water potential among species. This behaviour indicates a strategy consistent with "anisohydric" pattern: reduced control over leaf water potential in response to changing environmental conditions, therefore leading to a higher risk of xylem embolism formation (Hacke et al. 2007; Mcdowell et al., 2008).

Such anisohydric behaviour of the lower canopy is an important strategy to sustaining plant productivity, considering that droughtinduced mortality risk might be mitigated by some other compensatory mechanism such as xylem structural reinforcement or plasticity (Cosme et al., 2017; Fonti et al., 2010; Markesteijn, Poorter, Bongers, Paz, \& Sack, 2011). In fact, our results help to explain the low mortality rates observed in small trees (DBH $<20 \mathrm{~cm}$ ) in throughfall exclusion experiments in the Amazon (Da Costa et al., 2010; Nepstad, Tohver, Ray, Moutinho, \& Cardinot, 2007), and even the increased growth rates of small trees following the substantial mortality of larger trees during droughts at two Eastern Amazon forest sites (Brando et al., 2010; Rowland et al., 2015).

We suggest that these patterns are likely also reflected along tree ontogeny, though our data on mature trees of each species did not address this. Young trees of even dominant canopy species must start out with relatively shallow roots, and during this phase of development they may need a high degree of embolism resistance to survive in the dense understorey environment (Figure S7) where competition for space and water among smaller trees can be intense (Rice et al., 2004; Stark et al., 2015). Reduction in investment that confers greater embolism resistance would be consistent with access to deeper soil water reservoirs with greater root depth (Fonti et al., 2010). Indeed, a significant increase in $P_{50}$ along with $D B H$ during tree growth was observed across several species in Caxiuana forest (Rowland et al., 2015).

Despite deep water access, larger trees are generally more vulnerable to xylem embolism and appear to operate closer to their safety margins than do understorey trees (Figure 3c,d), particularly given the high-light and high-VPD conditions that they are frequently exposed to during droughts. Indeed, drought-induced mortality of larger trees has been observed in many areas of the Amazon forest (Bennett, McDowell, Allen, \& Anderson-Teixeira, 2015; Nepstad et al., 2007; Phillips et al., 2010; Rowland et al., 2015). Low $\mathrm{HSMP}_{50}$ may indicate that stomatal regulation takes the full advantage of the small safety range of xylem pressures (Choat et al., 2012), while running the risk of severe hydraulic failure in drought conditions extreme enough to deplete the deep soil water these trees use (Anderegg et al., 2016). Deep water access represents a competitive advantage in terms of water use, making it possible for trees to avoid drought and invest in growth, rather than investing in producing a very resistant hydraulic transport system (Stark et al., 2015). However, basic principles of plant physiology predict that vulnerability to drought stress increases with tree height; taller trees need to deal with higher VPD, light interception and hydraulic path length (McDowell \& Allen, 2015), which might be compensated by other water regulation strategies, such as leaf turgor loss avoidance (Bartlett, Scoffoni, \& Sack, 2012; Skelton, West, \& Dawson, 2015). Indeed, at the year-to-year scale (2014-2015), deeply rooted larger tree species showed a more isohydric behaviour (in terms of water potential regulation; Figure $3 \mathrm{~b}$ ).

Further studies need to investigate the minimum threshold of deep-root water access required for tree survival during prolonged drought. Taken together, our results suggest that long-term droughts might increase embolism risk in species with higher $P_{50}$ and $\mathrm{P}_{88}$ and, if associated with the depletion of nonstructural carbohydrates reserves beyond critical thresholds (Mcdowell et al., 2008; Sala, Woodruff, \& Meinzer, 2012), may lead to increased risk of large tree mortality. Furthermore, additional studies are needed to elucidate the effect of hydrological drought on decreasing deep water recharge and inducing canopy turnover and ecosystem changes in Amazon (Chitra-Tarak et al., 2018; Leitold et al., 2018; Taufik et al., 2017). Greater mortality in deep-rooted trees was observed during a drought in a dry tropical forest in India (Chitra-Tarak et al., 2018), and attributed to the delayed recharge of deeper water following drought. Additionally, periods with low groundwater recharge may amplify wildfire occurrence as observed in a tropical forest in Borneo (Taufik et al., 2017), and may intensify the recently observed increase wildfire in eastern Amazon (Aragão et al., 2018).

\section{2 | Estimated functional rooting depth}

Tree diameter is currently used in allometric models to estimate coarse root biomass (Gou et al., 2017; Tobin et al., 2007). Here we suggest an empirically based allometric model to estimate the effective rooting depth (EFRD) for a seasonal Amazon forest using DBH (Equation 5). However, some uncertainties should be considered.

When we examined EFRD responses using the bootstrapping estimates of parameters $m, n, k$ and $r$, the results yielded an uncertainty of 6 to $30 \mathrm{~m}$ depth in soil profile (Figure 1d and Figure S4). Despite this, the model was sufficiently sensitive to demonstrate a certain degree of vertical rooting depth partitioning as a function of tree $\mathrm{DBH}$ in all simulations; thus, we are confident about the existence of a rooting depth pattern in Tapajós forest that can be inferred by tree $\mathrm{DBH}$. The strong correlation between $\mathrm{DBH}$ and $\delta^{18} \mathrm{O}_{\mathrm{xylem}}$ and the isotopic mixing model results (Figures $1 \mathrm{c}$ and $2 \mathrm{c}$ ) supports the idea of larger trees using relatively large amounts of water below $1 \mathrm{~m}$ (and likely down to $13 \mathrm{~m}$ ). While we are aware that our results only provide a picture of water use dynamics during one dry period of a single year (the extreme drought of 2015), we also believe there is a substantial plasticity of root water uptake to allow for shifts in effective rooting depth in response to changes in soil dryness conditions (Couvreur, Vanderborght, Draye, \& Javaux, 2014; Doussan, Pierret, Garrigues, \& Pagès, 2006; Fan et al., 2017; Schröder, Javaux, Vanderborght, Körfgen, \& Vereecken, 2008).

An additional source of uncertainty is that xylem water stable isotope composition reflects a mixture of uptake from multiple depths (see Moreira et al., 2000; Romero-Saltos et al., 2005), considering that 
Equation (5) requires the predicted $\delta^{18} \mathrm{O}_{\text {xylem }}$ from Equation (3) to be used and this creates a noise in our estimates. However, the 2015/2016 ENSO induced both a strong isotopic gradient in the soil water, mainly above $1 \mathrm{~m}$ depth (Figure 1), as well as strong competition for water, likely leading to a disproportionate uptake of water by each tree from the deepest soil layers it had access to. Furthermore, the mixing model results highlight that even if xylem water stable isotope composition reflects uptake from multiple depths, there was a clear distinction of smaller trees using more shallow water $(<1 \mathrm{~m})$ and larger trees using deeper water (2-13 m; Figure 2). The uptake of water from multiple depths may occur in the deeper soil layers, but we were not able to clearly distinguish an isotopic signal in each layer below $1 \mathrm{~m}$ depth.

Our results are supported by the survey on root morphologies conducted at Tapajós showing that the dimorphic rooting habit with tap roots growing vertically towards deeper soil layers are strongly represented at this site (Oliveira et al., 2005). This contrasts with the pattern observed in a hyper-humid aseasonal Panamanian forest, where larger trees $(\mathrm{DBH}>50 \mathrm{~cm}$ ) acquired water from shallow soil layers (more $\delta^{18} \mathrm{O}$-enriched water) and small trees from soil up to $2 \mathrm{~m}$ depth (Meinzer et al., 1999). These authors concluded that larger trees invest more in widening their horizontal root distribution (Meinzer et al., 1999); however, we expect this shallow, extensive strategy to be most common in environments without a long and intense dry season, or in sites that lack a deep soil (Canadell et al., 1996; Fan et al., 2017). The strategy of competing for shallow soil water would seem to be advantageous only when soil moisture at these depths is fairly reliable, or if other drought stress avoidance strategies such as deciduous dormancy are employed. Intense competition for a limited amount of shallow soil water during an extended dry season would likely require high embolism resistance, especially for evergreen canopy trees which must endure high-VPD and high-radiation flux at the top of the canopy throughout the dry season.

Even with the aforementioned precautions, we highlight the model expressed in Equation (5) as a good approximation of the overall functional rooting depth in the Tapajós forest (Figure 3c). Evidence of root activity around $13 \mathrm{~m}$ depth in seasonal Amazon forest (Davidson et al., 2011; Ivanov et al., 2012; Markewitz et al., 2010; Nepstad et al., 1994), and the expected average maximum rooting depth for tropical evergreen forest of $15( \pm 5.4) \mathrm{m}$ (Canadell et al., 1996), lend substantial support to scaling up the EFRD for a large area in Tapajós (Rice et al., 2004). We can use simple-to-measure variables, such as $\mathrm{DBH}$, to parameterize model representations of difficult-to-measure underlying functions, such as rooting depth. It will be relevant to determine whether the EFRD-DBH relationship holds in nonseasonal tropical rainforests and whether we can better describe ecosystem processes by incorporating such relationships into land-surface and ecohydrological models.

\section{5 | CONCLUSIONS}

The distribution of leaf area and light environments in seasonal Amazon forests is integrally connected to the size (diameter) distribution of trees (Stark et al., 2015). We have confirmed that tree size is also related to the effective rooting depth (Ivanov et al., 2012), and demonstrated that such interdependence is associated with different hydraulic strategies. Specifically, our data show coordination between the rooting depth and embolism resistance within seasonal Amazon forests, suggesting a trade-off between drought avoidance (i.e. deep rooted) and drought tolerance (i.e. embolism-resistance). Drought-avoiding species are characterized by deep roots, which allow relatively little investment in mechanisms facilitating embolism resistance, as well as operation near the limit of hydraulic safety margin. This is the predominant strategy in canopy/overstorey trees with greater canopy exposure to light. Drought tolerance, the predominant strategy in shallow-rooted and light-limited understorey trees, is demonstrated by the lower $\mathrm{P}_{50}$ and $\mathrm{P}_{88}$ and high year-to-year variability in xylem water potential. These complementary strategies allow niche partitioning within the ecosystem and affect the structure of dominant species in the community, driven by both water and light availability. Further studies on these traits should be conducted in other tropical forests to evaluate the generality of these findings.

Capturing species variation in structural and physiological traits in a hyperdiverse tropical forest represents an enormous challenge for model parameterizations, but our results suggest that much of the variation can be captured through the fairly straightforward relationships between tree diameter, canopy position, rooting depth, and hydraulic trait parameters in seasonally dry tropical forests growing on deep soils. Our results also help to explain the dry season green-up and increase in productivity observed in seasonal Amazon forests as dependent on canopy trees' access to deep soil water (Restrepo-Coupe et al., 2016; Saleska et al., 2003). However, we stress that further research is needed to better constrain the partitioning of water use and forest productivity along vertical canopy gradient under a range of water-abundant and water-limiting conditions.

\section{ACKNOWLEDGEMENTS}

This work was supported by many research agencies. M.B., P.R.L.B., F.B. and L.P. were supported by CAPES PhD scholarship. M.A.V. and H.A. were supported by a NASA Interdisciplinary Science grant (NNX14AD31G). V.I. and S.R.S. acknowledge DOE Grant DE-SC0011078 ("GoAmazon"). M.B., R.S.O., L.A. and L.E.O.C.A. thank GO-AMAZON FAPESP (2013/50533-5) and L.E.O.C.A. thanks CNPq Productivity Fellowship (305054/20163). V.I., R.S.O. and M.B. also thank FAPESP-UoM (2014/50332-2) and FAPESP-Microsoft (2011/52072-0). We are also grateful to the LBA-INPA assistance in Santarém with special respect to Louro Lima, Adão Silva Santos, Cleuton Pereira, Sarah Mião, Elizangela Rebelo, Marduk (in memoriam), Neill Prohaska and Gregory Ewing. We also thank Dr. Michael Keller for reviewing and commenting in the manuscript. The authors confirm they do not have any conflict of interest. 


\section{AUTHORS' CONTRIBUTIONS}

M.B., M.A.V. and R.S.O. conceived the project and wrote the first version of this manuscript, along with H.A., L.F.A. and V.I. M.B., M.A.V., D.P. and J.D.D. collected field data. M.B., M.A.V., P.B., F.B., S.S., L.P. and V.I. contributed to data analyses. S.S. and L.E.O.C.A contributed with infrastructure at the field site. All authors contributed to the final version of the manuscript.

\section{DATA ACCESSIBILITY}

Data available from the Dryad Digital Repository: https://doi. org/10.5061/dryad.v704dj2 (Brum, 2018).

\section{ORCID}

Mauro Brum (iD http://orcid.org/0000-0002-9790-254X

Heidi Asbjornsen (iD http://orcid.org/0000-0001-8126-3328

\section{REFERENCES}

Aguinis, H., Gottfredson, R. K., \& Joo, H. (2013). Best-practice recommendations for defining, identifying, and handling outliers. Organizational Research Methods, 16(2), 270-301. https://doi. org/10.1177/1094428112470848

Anderegg, W. R. L., Klein, T., Bartlett, M., Sack, L., Pellegrini, A. F. A., \& Choat, B. (2016). Meta-analysis reveals that hydraulic traits explain cross-species patterns of drought-induced tree mortality across the globe. Proceedings of the National Academy of Sciences of the United States of America, 113(18), 2-7. https://doi.org/10.1073/ pnas.1525678113

Aragão, L. E., Anderson, L. O., Fonseca, M. G., Rosan, T. M., Vedovato, L. B., Wagner, F. H., ... Barlow, J. (2018). 21st Century drought-related fires counteract the decline of Amazon deforestation carbon emissions. Nature Communications, 9(1), 536.

Araya, Y. N., Silvertown, J., Gowing, D. J., Mcconway, K. J., Linder, H. P., \& Midgley, G. (2011). A fundamental, eco-hydrological basis for niche segregation in plant communities. New Phytologist, 189(1), 253-258. https://doi.org/10.1111/j.1469-8137.2010.03475.x

Bartlett, M. K., Scoffoni, C., \& Sack, L. (2012). The determinants of leaf turgor loss point and prediction of drought tolerance of species and biomes: A global meta-analysis. Ecology Letters, 15(5), 393-405. https://doi.org/10.1111/j.1461-0248.2012.01751.x

Baty, F., Ritz, C., Charles, S., Brutsche, M., Flandrois, J. P., \& DelignetteMuller, M. L. (2015). A toolbox for nonlinear regression in R: The package nlstools. Journal of Statistical Software, 66(5), 1-21. http:// www.jstatsoft.org/v66/i05/

Bennett, A. C., McDowell, N. G., Allen, C. D., \& Anderson-Teixeira, K. J. (2015). Larger trees suffer most during drought in forests worldwide. Nature Plants, 1(10), 15139. https://doi.org/10.1038/ nplants.2015.139

Berry, Z. C., Evaristo, J., Moore, G., Poca, M., Steppe, K., Verrot, L., ... McDonnell, J. (2017). The two water worlds hypothesis: Addressing multiple working hypotheses and proposing a way forward. Ecohydrology, 11(3), e1843. https://doi.org/10.1002/eco.1843

Bittencourt, P. R. L., Pereira, L., \& Oliveira, R. S. (2016). On xylem hydraulic efficiencies, wood space-use and the safety-efficiency tradeoff. New Phytologist, 211(4), 1152-1155. https://doi.org/10.1111/nph.14044

Bonetti, S., Feng, X., \& Porporato, A. (2017). Ecohydrological controls on plant diversity in tropical South America. Ecohydrology, 10(6). https:// doi.org/10.1002/eco.1853
Bowen, G. J., Wassenaar, L. I., \& Hobson, K. A. (2005). Global application of stable hydrogen and oxygen isotopes to wildlife forensics. Oecologia, 143(3), 337-348. https://doi.org/10.1007/s00442-004-1813-y

Brando, P. M., Goetz, S. J., Baccini, A., Nepstad, D. C., Beck, P. S. A., \& Christman, M. C. (2010). Seasonal and interannual variability of climate and vegetation indices across the Amazon. Proceedings of the National Academy of Sciences of the United States of America, 107(33), 14685-14690. https://doi.org/10.1073/ pnas.0908741107

Broedel, E., Tomasella, J., Cândido, L. A., \& Randow, C. V. (2017). Deep soil water dynamics in an undisturbed primary forest in central Amazonia: Differences between normal years and the 2005 drought. Hydrological Processes, 31(9), 1749-1759. https://doi.org/10.1002/ hyp.11143

Brum, M. (2018). Data from: Hydrological niche segregation defines forest structure and drought tolerance strategies in a seasonal Amazon forest. Dryad Digital Repository, https://doi.org/10.5061/dryad. v704dj2

Brum, M., Teodoro, G. S., Abrahão, A., \& Oliveira, R. S. (2017). Coordination of rooting depth and leaf hydraulic traits defines drought-related strategies in the campos rupestres, a tropical montane biodiversity hotspot. Plant and Soil, 420(1-2), 467-480. https:// doi.org/10.1007/s11104-017-3330-x

Burnham, K. P., \& Anderson, D. R. (2003). Model selection and multimode inference: A practical information-theoretic approach. Berlin, Germany: Springer Science \& Business Media.

Canadell, J., Jackson, R., Ehleringer, J., Mooney, H. A., Sala, O. E., \& Schulze, E. D. (1996). Maximum rooting depth of vegetation types at the global scale. Oecologia, 108, 583-595. https://doi.org/10.1007/ BF00329030

Canty, A., \& Ripley, B. (2016). boot: Bootstrap R (S-Plus) Functions. R package version 1.3-18.

Chitra-Tarak, R., Ruiz, L., Dattaraja, H. S., Kumar, M. S. M., Riotte, J., Suresh, H. S., .. Sukumar, R. (2018). The roots of the drought: Hydrology and water uptake strategies mediate forest-wide demographic response to precipitation. Journal of Ecology, 106, 1495-1507. https://doi.org/10.1111/1365-2745.12925

Choat, B., Jansen, S., Brodribb, T. J., Cochard, H., Delzon, S., Bhaskar, R., ... Zanne, A. E. (2012). Global convergence in the vulnerability of forests to drought. Nature, 491(7426), 752-755. https://doi. org/10.1038/nature11688

Christoffersen, B. O., Gloor, M., Fauset, S., Fyllas, N. M., Galbraith, D. R., Baker, T. R., ... Meir, P. (2016). Linking hydraulic traits to tropical forest function in a size-structured and trait-driven model (TFS v.1Hydro). Geoscientific Model Development, 9(11), 4227-4255. https:// doi.org/10.5194/gmd-9-4227-2016

Coplen, T. B. (2011). Guidelines and recommended terms for expression of stable-isotope-ratio and gas-ratio measurement results. Rapid Communications in Mass Spectrometry, 25(17), 2538-2560. https:// doi.org/10.1002/rcm.5129

Cosme, L. H. M., Schietti, J., Costa, F. R. C., \& Oliveira, R. S. (2017). The importance of hydraulic architecture to the distribution patterns of trees in a central Amazonian forest. New Phytologist, 215(1), 113-125. https://doi.org/10.1111/nph.14508

Couvreur, V., Vanderborght, J., Draye, X., \& Javaux, M. (2014). Dynamic aspects of soil water availability for isohydric plants: Focus on root hydraulic resistances. Water Resources Research, 50(11), 1-16. https:// doi.org/10.1002/2014WR015608

Da Costa, C. L., Galbraith, D., Almeida, S., Portela, B. T. T., da Costa, M., de Athaydes, J. S. I., ... Meir, P. (2010). Effect of 7 yr of experimental drought on the aboveground biomass storage of an eastern Amazonian rainforest. New Phytologist, 187(3), 579-591. https://doi. org/10.1111/j.1469-8137.2010.03309.x

Davidson, E., Lefebvre, P. A., Brando, P. M., Ray, D. M., Trumbore, S. E., Solorzano, L. A., ... Nepstad, D. C. (2011). Carbon inputs and water 
uptake in deep soils of an eastern Amazon forest. Forest Science, 57(1), 51-58. https://doi.org/10.1016/j.cognition.2008.05.007

Davison, A. C., \& Hinkley, D. V. (1997). Bootstrap methods and their applications (Vol. 1). Cambridge, UK: Cambridge University Press. https:// doi.org/10.1017/CBO9780511802843

Dawson, T. D., Mambelli, S., Plamboek, A. H., Templer, P. H., \& Tu, K. P. (2002). Stable isotopes in plant ecology. Annual Review of Ecology and Systematics, 33(1), 507-559. https://doi.org/10.1146/annurev. ecolsys.33.020602.095451

Doussan, C., Pierret, A., Garrigues, E., \& Pagès, L. (2006). Water uptake by plant roots: II - Modelling of water transfer in the soil root-system with explicit account of flow within the root system - Comparison with experiments. Plant and Soil, 283(1), 99-117. https://doi. org/10.1007/s11104-004-7904-z

Ehleringer,J.R.,\&Dawson,T.E.(1992).Wateruptakebyplants:Perspectives from stable isotope composition. Plant, Cell and Environment, 15(9), 1073-1082. https://doi.org/10.1111/j.1365-3040.1992.tb01657.x

Eller, C. B., Lima, A. L., \& Oliveira, R. S. (2016). Cloud forest trees with higher foliar water uptake capacity and anisohydric behavior are more vulnerable to drought and climate change. New Phytologist, 211(2), 489-501. https://doi.org/10.1111/nph.13952

Espírito-Santo, F. D. B., Shimabukuro, Y. E., Aragão, L. E. O., \& Machado, E. L. M. (2005). Análise da composição florística e fitossociológica da floresta nacional do Tapajós com o apoio geográfico de imagens de satélites. Acta Amazonica, 35(2), 155-173. https://doi.org/10.1590/ S0044-59672005000200006

Esquivel-Muelbert, A., Baker, T. R., Dexter, K. G., Lewis, S. L., ter Steege, H., Lopez-Gonzalez, G., ... Phillips, O. L. (2016). Seasonal drought limits tree species across the Neotropics. Ecography, 40(5), 618-629. https://doi.org/10.1111/ecog.01904

Evaristo, J., Mcdonnell, J. J., Scholl, M. A., Bruijnzeel, L. A., \& Chun, K. P. (2016). Insights into plant water uptake from xylem-water isotope measurements in two tropical catchments with contrasting moisture conditions. Hydrological Processes, 30(18), 3210-3227. https://doi. org/10.1002/hyp.10841

Fan, Y., Miguez-Macho, G., Jobbágy, E. G., Jackson, R. B., \& Otero-Casal, C. (2017). Hydrologic regulation of plant rooting depth. Proceedings of the National Academy of Sciences of the USA, 114(40), 10572-10577. https://doi.org/10.1073/pnas.1712381114

Fauset, S., Johnson, M. O., Gloor, M., Baker, T. R., Monteagudo, M. A., Brienen, R. J. W., ... Phillips, O. L. (2015). Hyperdominance in Amazonian forest carbon cycling. Nature Communications, 6, 6857. https://doi.org/10.1038/ncomms7857

Fonti, P., Von Arx, G., García-González, I., Eilmann, B., Sass-Klaassen, U., Gärtner, H., \& Eckstein, D. (2010). Studying global change through investigation of the plastic responses of xylem anatomy in tree rings. New Phytologist, 185(1), 42-53. https://doi. org/10.1111/j.1469-8137.2009.03030.x

García-Baquero, G., Silvertown, J., Gowing, D. J., \& Valle, C. J. (2016). Dissecting the hydrological niche: Soil moisture, space and lifespan. Journal of Vegetation Science, 27(2), 219-226. https://doi. org/10.1111/jvs.12353

Giardina, F., Konings, A. G., Kennedy, D., Alemohammad, S. H., Oliveira, R. S., Uriarte, M., \& Gentine, P. (2018). Tall Amazonian forests are less sensitive to precipitation variability. Nature Geoscience, 1, https://doi. org/10.1038/s41561-018-0133-5

Gou, M., Xiang, W., Song, T., Lei, P., Zhang, S., Ouyang, S., ... Wang, K. (2017). Allometric equations for applying plot inventory and remote sensing data to assess coarse root biomass energy in subtropical forests. BioEnergy Research, 10(2), 536-546. https://doi.org/10.1007/ s12155-017-9820-0

Hacke, U. G., Sperry, J. S., Feild, T. S., Sano, Y., Sikkema, E. H., \& Pittermann, J. (2007). Water transport in vesselless angiosperms: Conducting efficiency and cavitation safety. International Journal of Plant Sciences, 168(8), 1113-1126. https://doi.org/10.1086/520724
Hillebrand, H., Bennett, D. M., \& Cadotte, M. W. (2008). Concepts \& synthesis emphasizing new ideas to stimulate research in ecology consequences of dominance: A review of evenness effects on local and regional ecosystem processes. Ecology, 89(6), 1510-1520. https:// doi.org/10.1890/07-1053.1

Huete, A. R., Didan, K., Shimabukuro, Y. E., Ratana, P., Saleska, S. R., Hutyra, L. R., ... Myneni, R. (2006). Amazon rainforests green-up with sunlight in dry season. Geophysical Research Letters, 33(6), 1:4. https://doi.org/10.1029/2005GL025583

IBAMA. (2004). Plano de Manejo. Floresta Nacional do Tapajós, I, 2-165.

Ivanov, V. Y., Hutyra, L. R., Wofsy, S. C., Munger, J. W., Saleska, S. R., De Oliveira, R. C., \& De Camargo, P. B. (2012). Root niche separation can explain avoidance of seasonal drought stress and vulnerability of overstory trees to extended drought in a mature Amazonian forest. Water Resources Research, 48(12), 1-21. https:// doi.org/10.1029/2012WR011972

Jiménez-Muñoz, J. C., Mattar, C., Barichivich, J., Santamaría-Artigas, A., Takahashi, K., Malhi, Y., ... Van Der Schrier, G. (2016). Record-breaking warming and extreme drought in the Amazon rainforest during the course of El Niño 2015-2016. Scientific Reports, 6(1), 33130. https:// doi.org/doi:10.1038/srep33130

Kohyama, T. (1993). Size-structured tree populations in gap-dynamic forest - The forest architecture hypothesis for the stable coexistence of species. Journal of Ecology, 81(1), 131-143. https://doi. org/10.2307/2261230

Lee, J. E., Oliveira, R. S., Dawson, T. E., \& Fung, I. (2005). Root functioning modifies seasonal climate. Proceedings of the National Academy of Sciences of the United States of America, 102(49), 17576-17581. https://doi.org/10.1073/pnas.0508785102

Leitold, V., Morton, D. C., Longo, M., Dos-Santos, M. N., Keller, M., \& Scaranello, M. (2018). El Niño drought increased canopy turnover in Amazon forests. New Phytologist, 1:13. https://doi.org/10.1111/ nph.15110

Longo, M. (2013). Amazon forest response to changes in rainfall regime: Results from an individual-based dynamic vegetation model. Dissertation Thesis, Harvard University.

Malhi, Y., Aragao, L. E. O. C., Galbraith, D., Huntingford, C., Fisher, R., Zelazowski, P., ... Meir, P. (2009). Exploring the likelihood and mechanism of a climate-change-induced dieback of the Amazon rainforest. Proceedings of the National Academy of Sciences of the USA, 106(49), 20610-20615. https://doi.org/10.1073/pnas.0804619106

Marengo, J. A., Tomasella, J., Alves, L. M., Soares, W. R., \& Rodriguez, D. A. (2011). The drought of 2010 in the context of historical droughts in the Amazon region. Geophysical Research Letters, 38(12), 1-5. https://doi.org/10.1029/2011GL047436

Markewitz, D., Devine, S., Davidson, E. A., Brando, P., \& Nepstad, D. C. (2010). Soil moisture depletion under simulated drought in the Amazon: Impacts on deep root uptake. New Phytologist, 187(3), 592607. https://doi.org/10.1111/j.1469-8137.2010.03391.x

Markesteijn, L., Poorter, L., Bongers, F., Paz, H., \& Sack, L. (2011). Hydraulics and life history of tropical dry forest tree species: Coordination of species' drought and shade tolerance. New Phytologist, 191(2), 480-495.

McDowell, N. G., \& Allen, C. D. (2015). Darcy's law predicts widespread forest mortality under climate warming. Nature Climate Change, 5(7), 669-672. https://doi.org/10.1038/nclimate2641

Mcdowell, N., Pockman, W. T., Allen, C. D., Breshears, D. D., Cobb, N., Kolb, T., ... Yepez, E. A. (2008). Mechanisms of plant survival and mortality during drought: Why do some plants survive while others succumb to drought? New Phytologist, 178(4), 719-739. https://doi. org/10.1111/j.1469-8137.2008.02436.x

Meinzer, F. C., Andrade, L., Goldstein, G., Holbrook, M., Cavelier, J., \& Wright, J. (1999). Partitioning of soil water among canopy trees in a seasonally dry tropical forest. Oecologia, 121(3), 293-301. https:// doi.org/10.1007/s004420050931 
Meinzer, F. C., Johnson, D. M., Lachenbruch, B., McCulloh, K. A., \& Woodruff, D. R. (2009). Xylem hydraulic safety margins in woody plants: Coordination of stomatal control of xylem tension with hydraulic capacitance. Functional Ecology, 23(5), 922-930. https://doi. org/10.1111/j.1365-2435.2009.01577.x

Meir, P., Brando, P. M., Nepstad, D., Vasconcelos, S., Costa, A. C. L., Davidson, E., \& Cardinot, G. (2009). The effects of drought on Amazonian rain forests. Amazonia and Global Change, 186, 429-449. https://doi.org/10.1029/2009GM000882

Moreira, M. Z., Sternberg, L. D. L., \& Nepstad, D. C. (2000). Vertical patterns of soil water uptake by plants in a primary forest and an abandoned pasture in the eastern Amazon: An isotopic approach. Plant and Soil, 222(1-2), 95-107. https://doi. org/10.1023/A:1004773217189

Muggeo, V. M. R. (2008). segmented: An R package to fit regression models with broken-line relationships. $R$ News, 8/1, 20-25.

Muscarella, R., \& Uriarte, M. (2016). Do community-weighted mean functional traits reflect optimal strategies? Proceedings of the Royal Society B, 283(1827), 20152434. https://doi.org/doi:10.1098/ rspb.2015.2434

Nepstad, D. C., de Carvalho, C. R., Davidson, E. A., Jipp, P. H., Lefebvre, P. A., Negreiros, G. H., ... Vieira, S. (1994). The role of deep roots in the hydrological and carbon cycles of Amazonian forests and pastures. Nature, 372, 666-669. https://doi.org/10.1038/372666a0

Nepstad, D. C., Moutinho, P., Dias-Filho, M. B., Davidson, E., Cardinot, G., Markewitz, D., ... Guerreiros, J. B. (2002). The effects of partial throughfall exclusion on canopy processes, aboveground production, and biogeochemistry of an Amazon forest. Journal of Geophysical Research: Atmospheres, 107(D20), 8085. https://doi. org/10.1029/2001JD000360

Nepstad, D. C., Tohver, I. M., Ray, D., Moutinho, P., \& Cardinot, G. (2007). Mortality of large trees and lianas following experimental drought in an Amazon forest. Ecology, 88(9), 2259-2269. https://doi. org/10.1890/06-1046.1

Niinemets, Ü. (2010). Responses of forest trees to single and multiple environmental stresses from seedlings to mature plants: Past stress history, stress interactions, tolerance and acclimation. Forest Ecology and Management, 260(10), 1623-1639. https://doi.org/10.1016/j. foreco.2010.07.054

Oliveira, R. S., Christoffersen, B. O., Barros, F., Teodoro, G. S., Bittencourt, P., Brum, M. M. Jr., \& Viani, R. A. G. (2014). Changing precipitation regimes and the water and carbon economies of trees. Theoretical and Experimental Plant Physiology, 26(1), 65-82. https://doi.org/10.1007/ s40626-014-0007-1

Oliveira, R. S., Dawson, T. E., Burgess, S. S. O., \& Nepstad, D. C. (2005). Hydraulic redistribution in three Amazonian trees. Oecologia, 145(3), 354-363. https://doi.org/10.1007/s00442-005-0108-2

Parnell, A. (2016). simmr: A Stable Isotope Mixing Model. R package version 0.3. Retrieved from https://CRAN.R-project.org/package $=s i m m r$

Parnell, A. C., Phillips, D. L., Bearhop, S., Semmens, B. X., Ward, E. J., Moore, J. W., ... Inger, R. (2013). Bayesian stable isotope mixing models. Environmetrics, 24(6), 387-399. https://doi.org/10.1002/ env. 2221

Pereira, L., Bittencourt, P. R. L., Oliveira, R. S., Junior, M., Barros, F. V., Ribeiro, R. V., \& Mazzafera, P. (2016). Plant pneumatics: Stem air flow is related to embolism - New perspectives on methods in plant hydraulics. New Phytologist, 211(1), 357-370. https://doi.org/10.1111/ nph.13905

Pereira, L., Domingues-Junior, A. P., Jansen, S., Choat, B., \& Mazzafera, P. (2017). Is embolism resistance in plant xylem associated with quantity and characteristics of lignin? Trees, 32(2), 349-358. https://doi. org/10.1007/s00468-017-1574-y

Pereira, L., \& Mazzafera, P. (2012). A low cost apparatus for measuring the xylem hydraulic conductance in plants. Bragantia Campinas, 71, 583-587. https://doi.org/10.1590/S0006-87052013005000006
Phillips, O. L., Van Der Heijden, G., Lewis, S. L., López-González, G., Aragão, L. E. O. C., Lloyd, J., ... Amaral, I. (2010). Drought-mortality relationships for tropical forests. New Phytologist, 187(3), 631-646. https://doi.org/10.1111/j.1469-8137.2010.03359.x

Pina, A. L., Zandavalli, R. B., Oliveira, R. S., Martins, F. R., \& Soares, A. A. (2016). Dew absorption by the leaf trichomes of Combretum leprosum in the Brazilian semiarid region. Functional Plant Biology, 43(9), 851-861. https://doi.org/10.1071/FP15337

Piñeiro, G., Perelman, S., Guerschman, J. P., \& Paruelo, J. M. (2008). How to evaluate models: Observed vs. predicted or predicted vs. observed? Ecological Modelling, 216(3), 316-322. https://doi. org/10.1016/j.ecolmodel.2008.05.006

Pyle, E. H., Santoni, G. W., Nascimento, H. E. M., Hutyra, L. R., Vieira, S., Curran, D. J., ... Wofsy, S. C. (2009). Dynamics of carbon, biomass, and structure in two Amazonian forests. Journal of Geophysical Research: Biogeosciences, 114(1), 1-20. https://doi. org/10.1029/2007JG000592

R Core Team. (2017). R: A language and environment for statistical computing. Vienna, Austria: R Foundation for Statistical Computing. Retrieved from https://www.R-project.org/

Restrepo-Coupe, N., da Rocha, H. R., Hutyra, L. R., da Araujo, A. C., Borma, L. S., Christoffersen, B., ... Saleska, S. R. (2013). What drives the seasonality of photosynthesis across the Amazon basin? A crosssite analysis of eddy flux tower measurements from the Brasil flux network. Agricultural and Forest Meteorology, 182, 128-144. https:// doi.org/10.1016/j.agrformet.2013.04.031

Restrepo-Coupe, N., Levine, N. M., Christoffersen, B. O., Albert, L. P., Wu, J., Costa, M. H., ... Saleska, S. R. (2016). Do dynamic global vegetation models capture the seasonality of carbon fluxes in the Amazon basin? A data-model intercomparison Global Change Biology, 23(1), 1-18. https://doi.org/10.1111/gcb.13442

Rice, A. H., Pyle, E. H., Saleska, S. R., Hutyra, L., Palace, M., Keller, M., ... Wofsy, S. C. (2004). Carbon balance and vegetation dynamics in an old-growth Amazonian forest. Ecological Applications, 14(sp 4), 55-71. https://doi.org/10.1890/02-6006

Romero-Saltos, H., Sternberg, L. D. S. L., Moreira, M. Z., \& Nepstad, D. C. (2005). Rainfall exclusion in an eastern Amazonian forest alters soil water movement and depth of water uptake. American Journal of Botany, 92(3), 443-455. https://doi.org/10.3732/ ajb.92.3.443

Rowland, L., da Costa, A. C. L., Galbraith, D. R., Oliveira, R. S., Binks, O. J., Oliveira, A. A. R., ... Meir, P. (2015). Death from drought in tropical forests is triggered by hydraulics not carbon starvation. Nature, 528(7580), 119-122. https://doi.org/10.1038/nature15539

Sala, A., Woodruff, D. R., \& Meinzer, F. C. (2012). Carbon dynamics in trees: Feast or famine? Tree Physiology, 32(6), 1-12. https://doi. org/10.1093/treephys/tpr143

Saleska, S. R., Miller, S. D., Matross, D. M., Goulden, M. L., Wofsy, S. C., Da Rocha, H. R., ... Hutyra, L. (2003). Carbon in Amazon forests: Unexpected seasonal fluxes and disturbance-induced losses. Science, 302(5650), 1554-1557. https://doi.org/10.1126/science.1091165

Schröder, T., Javaux, M., Vanderborght, J., Körfgen, B., \& Vereecken, H. (2008). Effect of local soil hydraulic conductivity drop using a threedimensional root water uptake model. Vadose Zone Journal, 7(3), 1089-1098. https://doi.org/10.2136/vzj2007.0114

Schwinning, S., \& Kelly, C. K. (2013). Plant competition, temporal niches and implications for productivity and adaptability to climate change in water-limited environments. Functional Ecology, 27(4), 886-897. https://doi.org/10.1111/1365-2435.12115

Silvertown, J., Araya, Y., \& Gowing, D. (2015). Hydrological niches in terrestrial plant communities: A review. Journal of Ecology, 103(1), 93-108. https://doi.org/10.1111/1365-2745.12332

Skelton, R. P., West, A. G., \& Dawson, T. E. (2015). Predicting plant vulnerability to drought in biodiverse regions using functional traits. Proceedings of the National Academy of Sciences of the United 
States of America, 112(18), 5744-5749. https://doi.org/10.1073/ pnas. 1503376112

Sperry, J. S., Donnelly, J. R., \& Tyree, M. T. (1988). A method for measuring hydraulic conductivity and embolisms in xylem. Plant, Cell \& Environment, 11, 35-40. https://doi.org/10.1111/j.1365-3040.1988. tb01774.x

Sperry, J. S., Hacke, U. G., Oren, R., \& Comstock, J. P. (2002). Water de cits and hydraulic limits to leaf water supply. Plant, Cell \& Environment, 25(2), 251-263. https://doi.org/10.1046/j.0016-8025. 2001.00799.x

Stark, S. C., Enquist, B. J., Saleska, S. R., Leitold, V., Schietti, J., Longo, M., ... Oliveira, R. C. (2015). Linking canopy leaf area and light environments with tree size distributions to explain Amazon forest demography. Ecology Letters, 18(7), 636-645. https://doi.org/10.1111/ ele.12440

Stark, S. C., Leitold, V., Wu, J. L., Hunter, M. O., de Castilho, C. V., Costa, F. R. C., ... Saleska, S. R. (2012). Amazon forest carbon dynamics predicted by profiles of canopy leaf area and light environment. Ecology Letters, 15(12), 1406-1414. https://doi. org/10.1111/j.1461-0248.2012.01864.x

Steege, H., Pitman, N. C. A., Sabatier, D., Baraloto, C., Salomao, R. P., Guevara, J. E., ... Silman, M. R. (2013). Hyperdominance in the Amazonian Tree Flora. Science, 342(6156), 1243092-1243092. https://doi.org/10.1126/science.1243092

Sterck, F., Markesteijn, L., Schieving, F., \& Poorter, L. (2011). Functional traits determine trade-offs and niches in a tropical forest community. Proceedings of the National Academy of Sciences of the USA, 108(51), 20627-20632. https://doi.org/10.1073/pnas.1106950108

Tardieu, F. (1996). Drought perception by plants Do cells of droughted plants experience water stress? Plant Growth Regulation, 20(2), 93104. https://doi.org/10.1007/BF00024005

Taufik, M., Torfs, P. J., Uijlenhoet, R., Jones, P. D., Murdiyarso, D., \& Van Lanen, H. A. (2017). Amplification of wildfire area burnt by hydrological drought in the humid tropics. Nature Climate Change, 7(6), 428. https://doi.org/10.1038/nclimate3280

Tobin, B., Čermák, J., Chiatante, D., Danjon, F., Di lorio, A., Dupuy, L., ... Spanos, I. (2007). Towards developmental modelling of tree root systems. Plant Biosystems - An International Journal Dealing With All Aspects of Plant Biology, 141(3), 481-501. https://doi. org/10.1080/11263500701626283

Vieira, S., de Camargo, P. B., Selhorst, D., Da Silva, R., Hutyra, L., Chambers, J. Q., ... Trumbore, S. E. (2004). Forest structure and carbon dynamics in Amazonian tropical rain forests. Oecologia, 140(3), 468-479. https://doi.org/10.1007/s00442-004-1598-z

Vinya, R., Malhi, Y., Fisher, J. B., Brown, N., Brodribb, T. J., \& Aragao, L. E. (2013). Xylem cavitation vulnerability influences tree species' habitat preferences in miombo woodlands. Oecologia, 173(3), 711-720. https://doi.org/10.1007/s00442-004-1598-z

Wu, J., Guan, K., Hayek, M., Restrepo-Coupe, N., Wiedemann, K. T., Xu, X., ... Saleska, S. R.,. (2016). Partitioning controls on Amazon forest photosynthesis between environmental and biotic factors at hourly to inter-annual time scales. Global Change Biology, 23(3), 1240-1257. https://doi.org/10.1111/gcb.13509

Zhang, Y., Lamarque, L. J., Torres-Ruiz, J. M., Schuldt, B., Karimi, Z., Li, S., ... Delzon, S. (2018). Testing the plant pneumatic method to estimate xylem embolism resistance in stems of temperate trees. Tree Physiology, 38, 1016:1025. https://doi.org/10.1093/treephys/tpy015

\section{SUPPORTING INFORMATION}

Additional supporting information may be found online in the Supporting Information section at the end of the article.

How to cite this article: Brum M, Vadeboncoeur MA, Ivanov V, et al. Hydrological niche segregation defines forest structure and drought tolerance strategies in a seasonal Amazon forest. $J$ Ecol. 2019;107:318-333. https://doi.org/10.1111/1365$\underline{2745.13022}$ 